Research Article

\title{
A Systematic Approach for the Reliability Evaluation of Electric Connector
}

\author{
Ruoyu Wang ${ }^{\mathbb{D}}$, Liangjun $\mathrm{Xu}$, and Yilin Zhou \\ School of Artificial Intelligence, Beijing University of Posts and Telecommunications, Beijing 100876, China \\ Correspondence should be addressed to Ruoyu Wang; rywang@bupt.edu.cn
}

Received 16 February 2021; Revised 13 April 2021; Accepted 20 April 2021; Published 6 May 2021

Academic Editor: Yang Li

Copyright ( $\odot 2021$ Ruoyu Wang et al. This is an open access article distributed under the Creative Commons Attribution License, which permits unrestricted use, distribution, and reproduction in any medium, provided the original work is properly cited.

Under the trend of high density and miniaturization, the current that the connector transmits per unit volume is getting higher and higher, which makes the reliability design of the connector more challenging. Under the pressure of high performance and low cost requirements, the design has to be more accurate and more efficient. Thus, in the design process, a systematic approach for reliability evaluation is required. However, there is no valid enough approach that is integrated, well-organized, and quantitative. In this article, a systematic approach for the reliability evaluation of connector was proposed, and by applying it on a typical object named a blade-spring connector, the validity of this approach was verified. After the framework of this approach has been established, the methods and models needed were provided, including the method to build up material selection criterion and the assessment models of stress relaxation, thermal diffusion, and sliding wear, respectively. Then, the feasibility of a newly developed copper alloy on the connector and the reliability behaviors of this connector were determined through this approach. The unsatisfactory aspects of reliability were pointed out and some possible redesign choices were provided. Results and discussion revealed that the proposed approach is a helpful tool for designing electric connectors, especially on the reliability design.

\section{Introduction}

Electric connector is a kind of electromechanical component widely used in the fields of aerospace, vehicle, grid, and consumer electronics, etc. The function of connector is simple, which is offering an interface for current transmission between two systems, but the reliability of the connector is essential for the systems. Connector failure is the main reason for system malfunction $[1,2]$, and sometimes the effect is devastating [3]. Thus, the reliability should be built into the connector through appropriate design and be adequately evaluated to ensure that reliable performance has been realized. Under the pressure of lower cost and higher performance, more efficient and more accurate design and evaluation are demanded, which means that the potential of material and structure must be fully reached.

To realize this goal, we have to overcome two main difficulties. On the one hand, many factors, like design factors and degradation mechanisms, are interplayed and influence the reliability of the connector. For instance, the overheating of a flexible connector was caused by fretting, stress relaxation, thermal expansion, and intermetallics [4]. The failure of a bolt connector was the comprehensive result of corrosion, fretting, and sliding wear [5]. One design choice, which makes the reliability meet requirement under the effect of some factors, might lead to the reliability becoming unsatisfied when other factors have been taken into consideration. This can increase the number of redesigns or overdesigns if multiple factors and their interplay are not sufficiently recognized and handled by designers, which leads to inefficient design. On the other hand, because there are extensive applications of connectors, the material and structure that the connector might adopt are various, and the factors that influence the reliability of the connector are also varied with specific applications. In recent years, electric connection systems are becoming more and more complex; the design and evaluation of connector reliability based on the traditional trial and error way become unacceptable gradually. For making the process more efficient with sufficient accuracy to reduce the time to market, new 
conceptions, models, methods, and criterions extracted from engineering practice to enhance the ability of design and evaluation are desired.

During the past two decades, there have been a few studies concerning the topics above, promoting the development of design approaches and evaluation of connector performance. Fok et al. proposed a case-based design system prototype for the conceptual design of connector [6]. Designers can obtain design alternatives from past cases as the starting point for further evaluation or design modification. This system contains no physical factors related to the performance of connector, such as material, structure, or degradation mechanism. Thus, it cannot help designers analyze the performance, although it is a very friendly tool to increase efficiency. Buggy et al. established a knowledgebased material database of connectors [7], which enables designers to select the material rapidly. It makes design start with the objective determination of exact function instead of past designs, which improves the utilization of material potential and, therefore, design efficiency. The most valuable opinion of this study is highlighting the importance of material on the performance of connector. The material almost influences all the mechanisms that affect connector reliability. Just like Fok et al.[6], Buggy et al. did not analyze the physical factors related to the connector performance. Only the philosophy for establishing the database was given, but the detailed methods and procedures to build it were not provided, making it challenging for designers to extend this approach to other applications.

In general, the above approaches are both empirical and cannot offer sufficient knowledge on the physical relationships between the influence factors and the performance of the connector. Blauth et al.proposed an analytical method to optimize the number of contact springs for the design of connector [8]. Due to the inclusion of main structure parameters, designers can use this method to evaluate the effect of parameter variation on the performance of the connector and extend it to various applications. However, the performance degradation of the connector was not considered, which means that the method can only be adopted to analyze the reliability of the connector at the initial stage of operation.

During the whole design process, the analysis of reliability is very important and necessary. Early, Mroczkowski has been aware that [9] and stated that designers should relate the performance parameters of connector to degradation mechanisms to assist the design and evaluation of reliability. According to the detailed discussion on the usage of a comprehensive degradation model, Mroczkowski exhibited the advantages and potential of the physics of failure (POF) method compared with the traditional statistics-based method for fast and accurate reliability design and evaluation. However, this model is qualitative and does not provide the relationships between some other important factors, such as material and structure, and the reliability of connector, thus leaving a large room for improvement of the systematism and availability of this method.

Besides POF, computer simulation is another powerful tool for analyzing the performance of connector to accelerate design and evaluation and improve accuracy. Jörgens et al. investigated the mechanical behavior of insulation displacement connector based on the finite element method (FEM) [10]. The accurate prediction of connector performance was realized. The authors highlighted the availability and convenience of FEM on the performance analysis of connector. Not only FEM but also computational fluid dynamics was used by McGowan [11] to achieve more accurate evaluation results of the thermal performance of connector. The simulation results were further used to improve test methods. This research was an early one that integrates multiple methods to form an approach for the reliability evaluation of connector, which has shown the tendency of the approach for connector performance analysis to integration and systematism.

Neither the approach in [10], nor that in [11], was used to evaluate connector performance in the phase of reliability design. Thus, the authors did not sufficiently reach the potential of simulation methods on the reliability analysis of connector. Instead, Liao et al. built a connector durability evaluation model based on the damage model [12], the parameter values of which were determined by FEM. This study combined POF and FEM to form a fast and accurate approach for the reliability evaluation of connector, which further improved the level of integration. However, this approach only applies to the situation where fatigue is the main failure mechanism of the connector and does not include the effects of material, structure, and other potential degradation mechanisms on the connector reliability. Further, Feng et al. proposed a technical framework based on POF and FEM [13], according to which the quantitative relationship between the lifetime of the connector and the parameters of material, structure, and environment can be built for the evaluation of the ultimate vibration load the connector can endure, to improve reliability design. The authors sophisticatedly took advantage of the superiority of POF and FEM on the reliability analysis of connector, and thus, a more systematic approach has been established. Regrettably, this approach does not consider the effect of multiple degradation mechanisms on the reliability, making it only apply to the situation where the fretting of connector happens because of vibration.

Recently, a systematic approach for the reliability design of connectors was proposed by Zhu et al.[14]. This approach is based on the systematic analysis of the performance of connector under the influence of multiple design factors and degradation mechanisms. It has a good level of integration and it is helpful for designers to carry out a relatively complete design. The fly in the ointment is that the authors did not take into consideration the effect of material, which is a key factor in the function and reliability of connector. In addition, the interplay between different design factors and degradation mechanisms was not included. This makes the approach unordered, which might lead to unnecessary redesigns.

It is obvious that the tendency of the analysis approach for connector performance is systematic, integrated, and quantitative, which is also the concern of our study. For the further improvement of efficiency, the approach would 
better be well-organized. Here, a systematic approach for the reliability evaluation of electric connector is proposed to help designers analyze connector performance and optimize connector reliability. The advantages of our approach are outlined as follows:

(1) It applies to the whole design process of the connector, including the function design phase and reliability design phase, which has a higher level of systematism and integration than the previous approaches.

(2) Multiple design factors and degradation mechanisms and their interplay have been taken into consideration. The framework is well-organized to provide order steps for evaluating connector performance, which has not been considered by the previous approaches.

(3) Based on POF and FEM, the quantitative methods and models of all the steps are provided. Especially, a novel method to build up the material selection criterion of the connector and a novel quantitative thermal diffusion evaluation model are proposed, which can fast analyze the performance of the connector during the design process.

A case was given to show the validity and superiority of this approach. This approach can help designers find references from the start point of a design process to the end to prevent them from consuming plenty of time for searching needed methods at different design phases. Because the interplay between influence factors and the probable conflicts between the design choices of different steps has been sufficiently considered, the reliability evaluation results obtained based on the well-organized steps can provide the guide for design modification and avoid unnecessary redesigns as much as possible. Further, POF and FEM were flexibly adopted, which supports the framework of this approach in being easily modified to match other applications without accuracy loss.

The remainder of this article is organized as follows. In Section 2, the approach framework is presented. In Section 3, the analysis object is introduced and the needed methods and models are built. In Section 4, evaluation results are presented. In Section 5, the results are discussed. In Section 6, this work is concluded.

\section{Framework}

The design procedure of the connector consists of two phases. The first phase is function design, during which structure is dimensioned and materials are chosen, based on their feasibility on the function realization of the connector. Then, the second phase is the reliability design phase. The ability of connectors to perform a specific function within a specific time and in a specific environment has to be ensured. If this ability does not meet the requirement, design improvement should be carried out, such as the redesign of structure [15], the replacement of material [16], or the adoption of certain process technique [17]. Without evaluation in the reliability design phase, the failure of the connector might happen ahead of schedule. During running, the performance of the connector will degrade under the effects of various mechanisms, which means that the indicator of performance, e.g., contact resistance, contact force, or temperature rise, might reach the extreme value that the system can endure before the expected lifespan.

Further, the two phases can be divided into many steps. No matter in what step, the current performance of the connector should be quantitatively assessed to ensure that the current design choices are adequate. The assessment order on the factors that influence the design choices should be well-organized to avoid making the design choices of a step conflicting with those of other steps. For instance, the contact performance has been redesigned, e.g., replacing surface material after a step. Then, suppose that the next step points out that the substrate material of the connector has to be replaced. This replacement might change the contact performance and then make the previous redesign invalid.

Here, an integrated and well-organized framework used in the design process for evaluating the reliability of the connector is proposed, as shown in Figure 1.

This framework is divided into three modules. In the first module, a preliminary structure of the connector is dimensioned based on space, sheet material, and termination mode. Then, the materials for function realization are determined on this structure. At this step, the material selection criterion, which lies in electrothermal, contact, and structure analysis, is required. In some situations, the ability of material has not been sufficiently played. Thus, structure optimization should be done to improve the performance of the connector to make the potential of material and structure fully reached.

In the second module, the degradation of the connector is evaluated. From the material point of view, there are two groups of mechanisms that influence the degradation of the connector. One group affects substrate material and another affects surface material. Because substrate degradation usually makes surface degradation worse $[5,18]$ and the opposite condition hardly happens, the assessment of the substrate degradation should be carried out first. The surface of the substrate is commonly plated or coated with thin metal films, such as gold [19], silver [20], or tin [21], to protect contacts from degrading so fast. However, sometimes, the film is not well compatible with the substrate and some negative effects will happen, such as thermal expansion [22], diffusion [23], and intermetallics [24]. Thus, the validity of surface prevention should be evaluated to ensure that the benefits which the film offers are more than the side effects. After the surface prevention has been determined as valid, the endurance of surface material should be assessed. If either the prevention validity or the endurance validity is not up to requirements, design improvement should be carried out.

In the third module, the anti-overcurrent ability of the connector is assessed. This is because, after the design of structure, the selection of material, the degradation evaluation, and the finish of corresponding design improvements, the connector is in a relatively perfect state. In the testing of 


\begin{tabular}{|c|c|c|}
\hline Supportive methods & Steps & Outputs \\
\hline Material selection criterion & & Preliminary structure \\
\hline Electrothermal analysis & $\downarrow$ & \\
\hline Contact analysis & Material selection & Initial design \\
\hline Structure analysis & Structure optimization & to be evaluated \\
\hline \multirow{4}{*}{$\begin{array}{l}\text { Degradation mechanisms } \\
\text { Degradation evaluation models }\end{array}$} & $\begin{array}{c}\text { Substrate material } \\
\text { degradation assessment } \\
\downarrow\end{array}$ & $\begin{array}{l}\text { Substrate material } \\
\text { lifetime \& reliability }\end{array}$ \\
\hline & Surface prevention & \multirow{3}{*}{$\begin{array}{c}\text { Surface material } \\
\text { lifetime \& reliability }\end{array}$} \\
\hline & $\begin{array}{c}\text { validity assessment } \\
\downarrow\end{array}$ & \\
\hline & $\begin{array}{l}\text { Surface endurance } \\
\text { assessment }\end{array}$ & \\
\hline Transient thermal analysis & $\begin{array}{l}\text { Anti-overcurrent } \\
\text { ability assessment }\end{array}$ & Anti-overcurrent ability \\
\hline
\end{tabular}

Figure 1: The framework of the reliability evaluation approach.

connector, overcurrent testing is generally considered as the gold standard of the performance of the connector, and in practice, overcurrent does happen [25]. The assessment results of this ability can be references for testing or further design improvement.

\section{Methodology}

3.1. Analysis Object. A newly developed copper alloy named $\mathrm{Cu}-20 \mathrm{Zn}-1.5 \mathrm{Ni}-0.34 \mathrm{Si}$ [26] was requested to replace the substrate material of a spring-blade connector. This connector consists of a blade and four springs, as shown in Figure 2. After the two parts are mated by insertion, current can be transmitted from one termination across contacts to another termination. The surfaces of all contacts are plated with gold with a thickness of $1 \mu \mathrm{m}$. A nickel underplate with a thickness of $2 \mu \mathrm{m}$ between the substrate and the gold finish is adopted by every spring contact surface. The specified function of this connector is transmitting the rated current of $70 \mathrm{~A}$ without making the maximum bulk temperature of the connector exceed $125^{\circ} \mathrm{C}$ under the environment temperature of $20^{\circ} \mathrm{C}$. The specified lifetime of the connector is 5 years.

Whether this new alloy can be adopted depends firstly on whether it can realize the function. Thus, a criterion for analyzing the feasibility of material is needed. After the function has been realized, the reliability of the connector should be evaluated. For this kind of structure, the contact force between every pair of spring and blade will continuously decrease because of stress relaxation [27]. The reduction of the contact force makes contact resistance become higher and the generation of Joule heat becomes more. For a gold-copper system, the effect of thermal diffusion should be considered because it will increase the contact resistance [28]. For this connector, the surface of the blade is a gold-copper system. The connector is requested to be quarterly separated for the regular inspection of the mother system. Thus, sliding periodically occurs, which leads to wear on the contact surfaces. Although the times of sliding are few, the wear endurance of the gold finish should be assessed because the contact force of this connector is relatively high.

3.2. Material Selection Criterion. Resumptively, the material selection criterion can be summarized that for a material with certain conductivity, the mechanical strength of this material must be high enough to provide the required contact force to get a sufficiently low contact resistance to make the maximum bulk temperature of the connector meet specification.

Different materials with different values of conductivity lead to different values of temperature under the same rated current and the same heat dissipation environment, supposed that there is no contact resistance. After the heat generation of the contact resistance has been considered, the temperature becomes higher. There is a specified upper limitation of the temperature and thus, a value exists that the contact resistance should be lower than it. This value varies with the material of the substrate and it can be analyzed by electrothermal FEM. In addition, the contact voltage drop between two contact surfaces would better be lower than $20 \mathrm{mV}$ [29] to avoid contact supertemperature being much high to soften the contacts. Because the current that flows through every pair of contacts is $17.5 \mathrm{~A}$, the contact resistance of every contact must be lower than $1.142 \mathrm{~m} \Omega$.

When the substrate materials of two contact parts are the same, the contact resistance $R_{c}$ can be calculated by the following formula [30]:

$$
R_{c}=\frac{\rho_{s}}{2} \sqrt{\frac{\xi \pi H}{F}},
$$

where $\rho_{s}, \xi, H$, and $F$ is substrate material resistivity, an empirical coefficient, surface hardness, and contact force, respectively.

Contact surface material is gold, and thus, $H$ and $\xi$ are constant. For a given substrate material, the maximum 


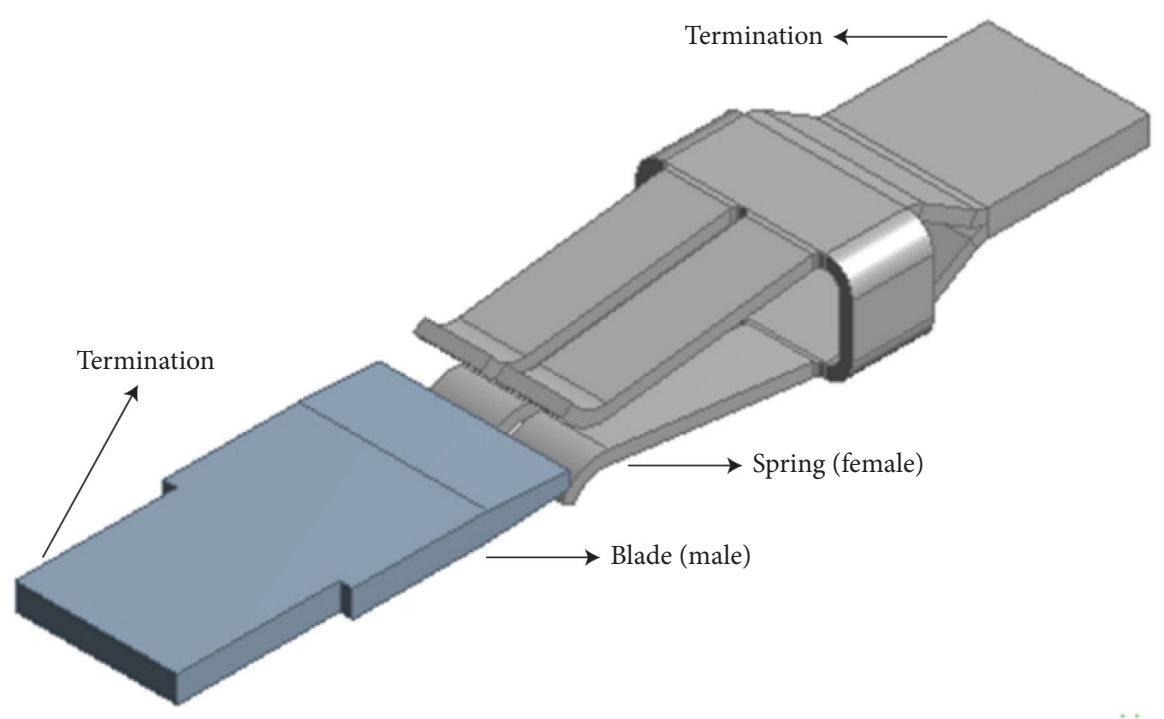

FIgURE 2: Analysis object: a spring-blade connector.

allowable contact resistance decides the minimum contact force that a spring has to provide. For the connector shown in Figure 2, the spring is an irregular beam, the restoring force of which equals contact force. There is no existing model for describing the relationship between the restoring force of this beam and its maximum stress. This relationship can be analyzed by static structure FEM. Based on that, the yield strength that the material of the spring should have can be determined.

To sum up, for a connector that its structure dimension has been known, a relationship between conductivity and strength about the substrate material of this connector can be established based on an analysis sequence shown in Figure 3. After this relationship has been determined, the feasibility of any alternative material on function realization can be analyzed.

3.3. Stress Relaxation Evaluation Model. After the optimization of the structure has been finished, the initial restoring force of every spring can be determined. According to the maximum allowable contact resistance, the minimum allowable contact force can be determined. Then, the maximum allowable relaxation percentage $D_{u p}$ can be determined. According to the Arrhenius equation, the effect of metal relaxation on the contact force can be expressed by the following formula [31]:

$$
D=t^{k} e^{\left(A-\frac{B}{T}\right),}
$$

where $D$ is the number of relaxation percentage, $t$ is time, $k$, $A$, and $B$ are material-related coefficients, and $T$ is absolute temperature.

For a given material, the values of $k, A$, and $B$ can be found in the established material database or be measured by experiments [32]. After the connector has been put into use, it has an initial maximum temperature noted as $T_{i}$. The maximum allowable temperature is noted as $T_{m}$, which is higher than $T_{i}$. It is inappropriate to take $T_{i}$ or $T_{m}$ into Equation (2) because adopting $T_{i}$ will underestimate and adopting $T_{m}$ will overestimate the value of $D$. A more accurate method is calculating the mean value of $T_{i}$ and $T_{m}$ to take this value into Equation (2). The specified life of the connector is noted as $t_{d}$. The values of $k, A, B, t_{d}$ and the mean value of $T_{i}$ and $T_{m}$ are taken into Equation (2) to determine $D$. If $D \leq D_{u p}$, the reliability of the connector under stress relaxation meets the requirement.

3.4. Thermal Diffusion Evaluation Model. The growth kinetics of oxidation film on copper in clean air follows the relationship as shown in the following formula [33]:

$$
d=K \frac{1}{n},
$$

where $d$ is film thickness, $n$ is a function of temperature, and $K$ is a function of material and temperature, respectively. Because oxidation is a process obviously thermally activated, $K$ can be expressed by the Arrhenius equation [34]. Thus, Equation (3) can be rewritten as follows:

$$
d=e^{-\frac{Q_{O}}{R T} \frac{1}{n}}
$$

where $Q_{o}$ is the activation energy of oxidation and $R$ is the gas constant $\left(8.314 \mathrm{~J} \cdot \mathrm{mol}^{-1} \mathrm{~K}^{-1}\right)$.

When the copper surface is plated or coated with gold, oxidation cannot directly happen on the copper. Copper atoms have to diffuse through the gold to the surface first and then react with the environment. In this situation, the concentration of the copper atoms in gold, noted as $C_{\mathrm{Cu}}$, influences reaction rate. Under the mechanism of diffusionoxidation, the growth kinetics of oxidation film can be rewritten as follows: 


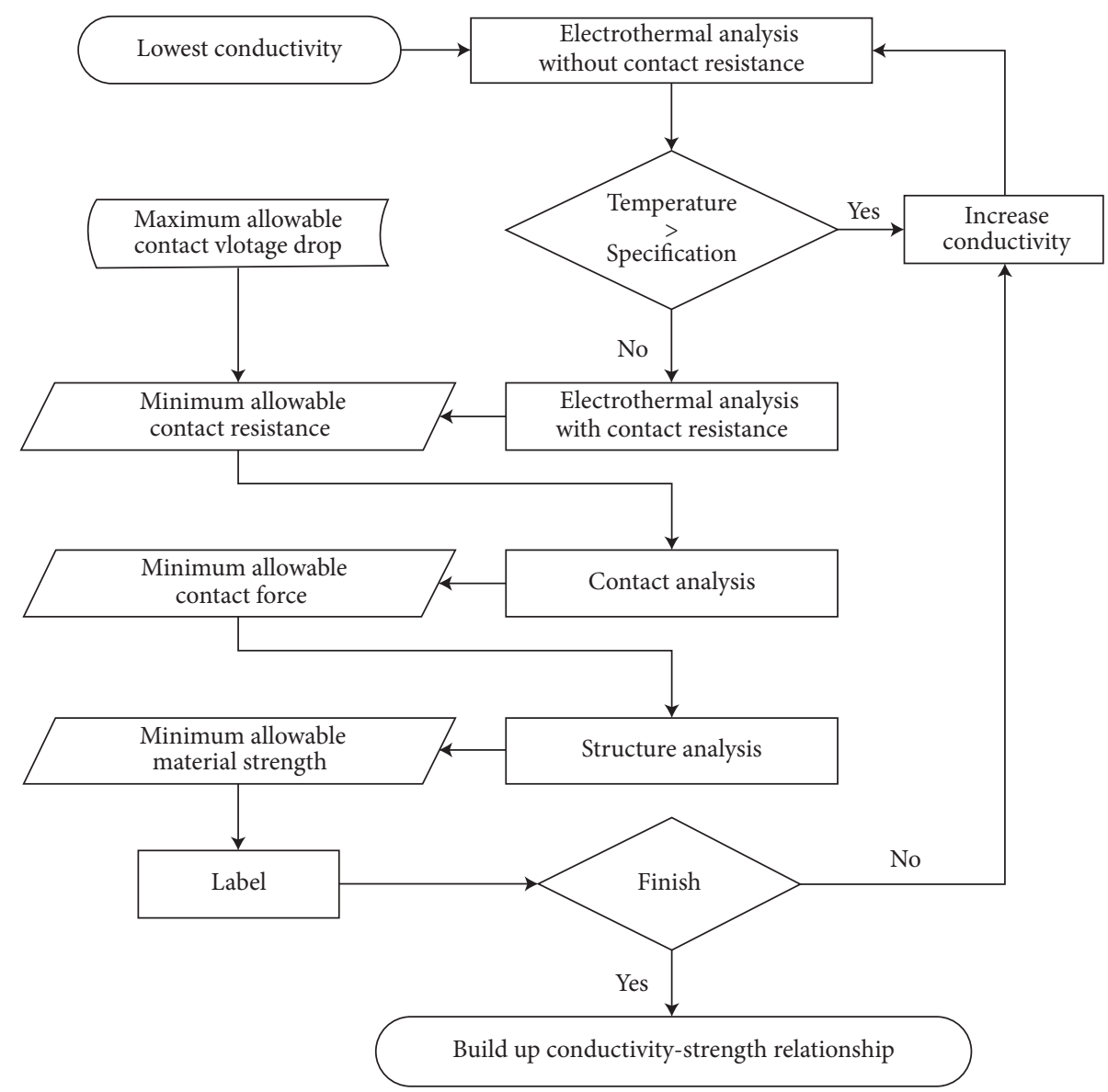

FIGURE 3: The analysis sequence for establishing the material selection criterion.

$$
d=f\left(C_{C u}\right) e^{-\left(Q_{T D} / R T\right)} t^{1 / n}
$$

where $f\left(C_{C u}\right)$ is a function of $C_{C u}$ and $Q_{T D}$ is the activation energy of the diffusion-oxidation.

Over the temperature range of $50^{\circ} \mathrm{C}-150^{\circ} \mathrm{C}$, the growth of oxidation film follows parabolic kinetics [35], i.e., $n=2$. The relationships between $d$ and $C_{C u}$ at $150^{\circ} \mathrm{C}$ under various times and the fact that $Q_{T D}$ is about $1.54 \mathrm{eV}(148587 \mathrm{~J} / \mathrm{mol})$ below $150^{\circ} \mathrm{C}$ have been given by [35]. Based on the conclusions, Equation (5) can be fitted as follows:

$$
d=\alpha C_{C u}^{(\beta T-\gamma)} e^{-\left(Q_{T D} / R T\right)} t^{1 / n},
$$

where $\quad \alpha=2.2 \times 10^{19} \AA / \mathrm{h}^{0.5}, \quad \beta=0.038 \mathrm{~K}^{-1}, \quad$ and $\quad \gamma=14$, respectively.

The relationships between $d$ and $t$ at $125^{\circ} \mathrm{C}$ and $150^{\circ} \mathrm{C}$ under different $C_{C u}$ (at.\%) were calculated by Equation (6), and the corresponding values calculated based on the experiments were extracted [35]. The results are plotted in Figure 4, which shows that the model built here can effectively describe the growth of oxidation film.

In Equation (6), $C_{C u}$ is a constant. However, in practice, $C_{C u}$ is varying with time in the gold-copper system of the connector. Thus, Equation (6) has to be modified. There is no copper in gold initially and as time goes on, $C_{C u}$ gradually increases. The interdiffusion mode between copper and gold is Gaussian, and there is [36]:

$$
C(x, t)=\frac{1}{2} \operatorname{erfc}\left[\frac{x}{2 \sqrt{D_{T} t}}\right],
$$

where $x$ is the distance from a point in the gold film to the interface of copper and gold, $C(x, t)$ is the concentration (at.\%) of copper at this point at the time of $t, \operatorname{erfc}$ is the complementary error function, and $D_{T}$ is diffusion coefficient, respectively.

The diffusion coefficient $D_{T}$ can be calculated by the following [36]:

$$
D_{T}=D_{0} e^{-\frac{Q_{D}}{R T}},
$$

where $D_{0}$ is the frequency factor and $Q_{D}$ is the activation energy of the diffusion.

For a gold film with the thickness of $h$, the average concentrate of copper at the time of $t$ is noted as $C_{a}(t)$. According to the mean value theorems for definite integrals, $C_{a}(t)$ can be calculated by the following:

$$
C_{a}(t)=\frac{1}{h} \int_{0}^{h} C(x, t) d x .
$$




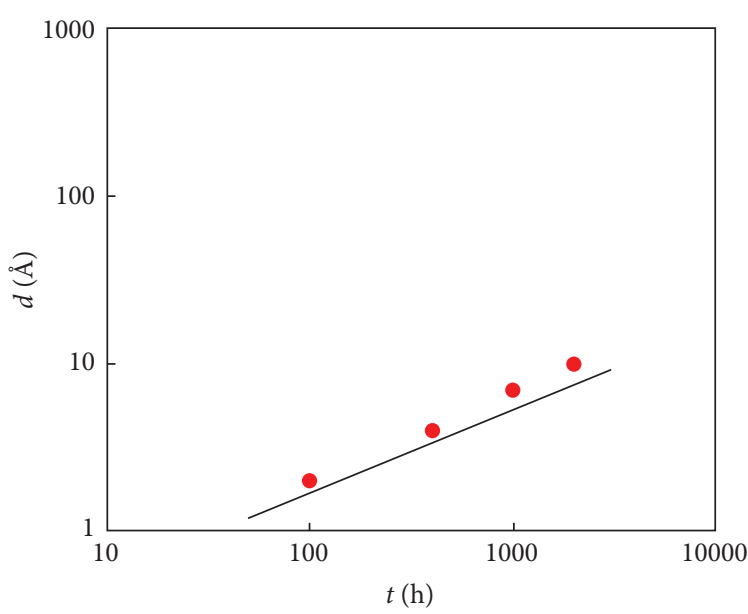

- Calcluated by [35]

— Calcluated by Eq. (6)

(a)

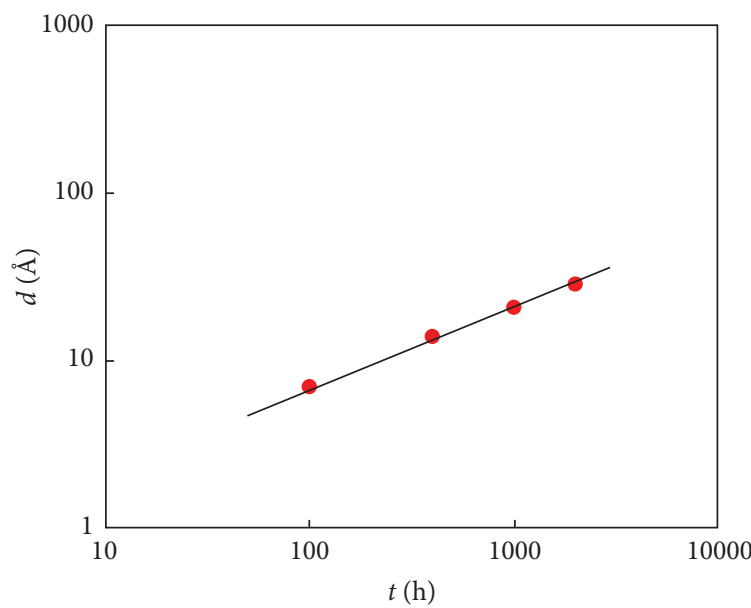

- Calcluated by [35]

— Calcluated by Eq. (6)

(c)

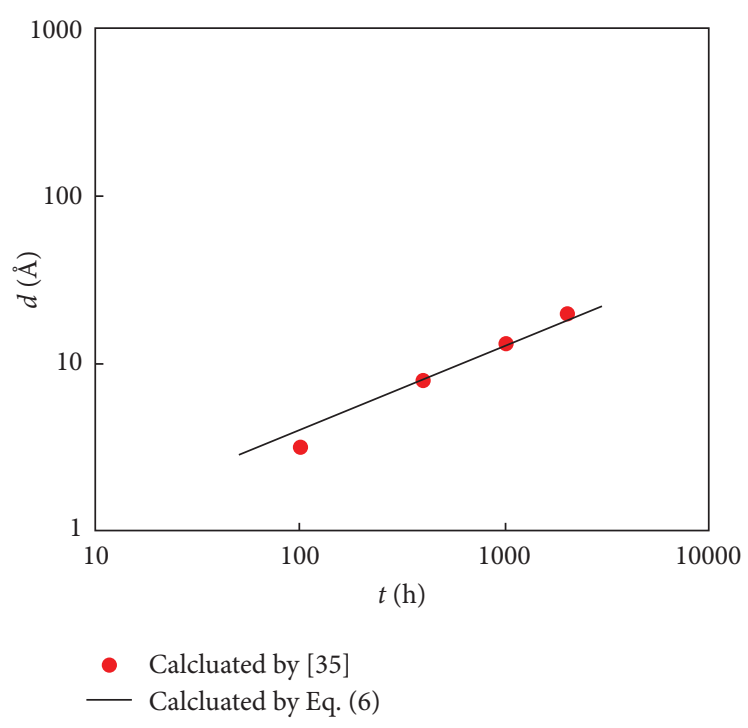

(b)

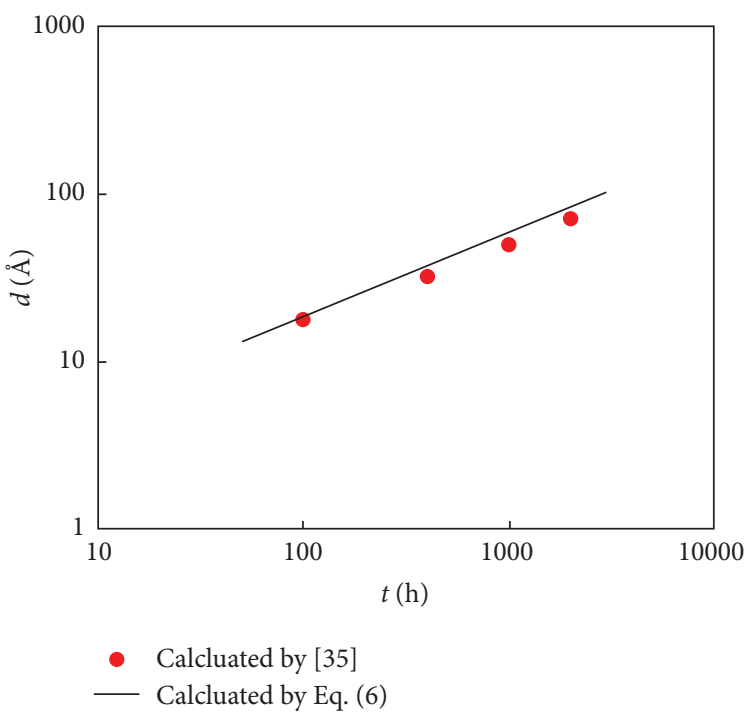

(d)

Figure 4: The relationships between $d$ and $t$. (a) $C_{c u}=0.26, T=125^{\circ} \mathrm{C}$; (b) $C_{c u}=0.57, T=125^{\circ} \mathrm{C}$; (c) $C_{c u}=0.26, T=150^{\circ} \mathrm{C}$; $(\mathrm{d}) C_{c u}=0.43$, $T=150^{\circ} \mathrm{C}$.

Furthermore, Equation (6) can be transformed into the following form:

$$
S=\left(\frac{d}{\alpha e^{-Q_{T D} / R T}}\right)^{n}=\left[C_{C u}^{(\beta T-\gamma)}\right]^{n} \cdot\left(\frac{1}{t n}\right)^{n}=V \cdot t_{s},
$$

where $S$ can be seen as a generalized distance, $V$ can be seen as a generalized rate, and $t_{s}$ can be seen as a generalized time, respectively.

In the situation expressed by Equation (6), the growth of $d$ can be seen as a motion with a uniform rate. In the situation expressed by Equation (10), the growth of $d$ can be seen as a motion with an accelerated rate. Thus, $d$ can be calculated by definite integral once the relationship between $V$ and $t_{s}$ has been known. This relationship can be fitted based on calculating the values of $C_{a}(t)$ under various times.

A pair of contact is not insulating totally if the oxidation film on the contact surface is not too thick. Current can be conducted across the film through tunnel effect. Tunnel resistivity $\rho_{t}$ can be calculated by the following formula [37]:

$$
\rho_{t}=\frac{10^{-22}}{2} \cdot \frac{A_{t}^{2}}{1+A_{t} B_{t}} e^{A_{t} B_{t}} \Omega c m^{2}
$$

where $A_{t}$ and $B_{t}$ can be calculated by the following [37]: 


$$
\left\{\begin{array}{l}
A_{t}=7.32 \times 10^{5} \times\left(d-\frac{7.2}{\Phi}\right), \\
B_{t}=1.265 \times 10^{-6} \times \sqrt{\Phi-\frac{10}{d \varepsilon_{r}}}
\end{array}\right.
$$

where $\Phi$ is the work function and $\varepsilon_{r}$ is relative permittivity.

For a given material, $\Phi$ and $\varepsilon_{r}$ are known constants. After $d$ has been determined, $\rho_{t}$ can be obtained. Then, the total contact resistance of this contact pair can be calculated by the following [37]:

$$
R_{c}=\frac{\rho_{s}}{2} \sqrt{\frac{\xi \pi H}{F}}+\frac{\rho_{t} \xi H}{F} .
$$

Under a certain temperature condition, $R_{c}$ at any time can be obtained by taking all the known parameters into Equation (7) to Equation (13). Then, whether the reliability of the connector under the mechanism of thermal diffusion meets requirement can be judged.

3.5. Sliding Wear Evaluation Model. Gold contacts are worn mainly by an adhesive process, the detailed mechanism of which is called prow formation [38]. In this process, metal transfers from the part with a larger surface, i.e., the blade surface, to the smaller surface, i.e., the spring surface. Repeating sliding increases the hardness of the blade surfaces by work hardening. Once the hardness of the blade surfaces has reached that of the prows, the spring surfaces begin to wear, and the wear mechanism transfers to rider wear [39]. For the consideration of safety, the wear mechanism should not transfer from the prow formation to the rider wear within specified sliding cycles. This is because once the spring surfaces have begun to wear, material loss along the normal direction is very fast due to the very small area which takes part in the wear process.

An equation exists that can describe the required sliding times for the transition of wear mechanism from the prow formation to the rider wear in the following form [39]:

$$
N_{s}=k_{s} \frac{L}{F}
$$

where $N_{s}$ is the sliding times for this transition, $k_{s}$ is a material-correlated parameter, and $L$ is the track length of one sliding, respectively.

The spring surfaces do not wear in the prow formation process, but the blade surfaces wear. Thus, the thickness of gold gradually decreases. Before the gold has been worn out, contact resistance will not increase, and thus, the wear will not increase the temperature of the connector. Once the gold has been worn out, copper will be exposed to the environment. This is dangerous because copper can be easily oxidated or corroded. Thus, the gold film of the blade should not be worn out within the specified lifetime. The wear of one surface of the blade can be described by the Archard mode:

$$
W=k_{w} \frac{F L_{w}}{H}
$$

where $W$ is total wear volume, $k_{w}$ is the coefficient of wear, and $L_{w}$ is total sliding distance, respectively. The width of wear track $w_{w}$ can be calculated by the following [30]:

$$
w_{w}=2 \alpha_{c}=2 \sqrt{\frac{F}{\pi \xi H}},
$$

where $\alpha_{c}$ is the radius of a contact point.

According to Equations 15 and 16, the wear depth $h_{w}$ of every sliding cycle (one insertion and one withdrawal, which means two times of sliding) can be expressed by the following:

$$
h_{w}=k_{w} \sqrt{\frac{\xi \pi F}{H}} .
$$

To make sure of the endurance of contact surface, two requirements have to be satisfied. Firstly, $N_{s}$ should not be lower than the specified sliding lifetime, which means that $N_{s} \geq 40$ (5 years, 4 cycles per year, and 2 times per cycle). Secondly, $h$ should not be lower than the total wear depth, which means that $h \geq 20 h_{w}$.

\section{Evaluation Results}

4.1. Evaluation of Material and Structure. Firstly, the material selection criterion of the connector was developed based on the analysis sequence shown in Figure 3. Finite element (FE) analysis was carried out on the platform of Ansys Workbench 18.2. According to symmetry, 1/4 model for the FE analysis was built, as shown in Figure 5. The length of the cable is $897 \mathrm{~mm}$, which is not shown. This length is long enough to take the effect of thermal conduction on the connector into consideration. Copper wire radius is $2.25 \mathrm{~mm}$ and the insulating layer thickness is $0.75 \mathrm{~mm}$. The thickness of the blade and the spring is $0.5 \mathrm{~mm}$. The material parameters of the cable are listed in Table 1.

The investigated electric conductivity range of copper alloy substrate was $15 \%-40 \%$ IACS. Initially, the values of $15 \%, 20 \%, 25 \%, 30 \%, 35 \%$, and $40 \%$ IACS were selected for analysis, respectively. Under every analysis round, the temperature coefficient of resistance $\sigma$ and the thermal conductivity $\lambda$ of the substrate were not known, which were the needed parameters by electrothermal FE analysis. Before the analysis, the relationship between $\lambda$ and $\sigma$ and that between $c_{t}$ and $\sigma$ had been fitted according to the database (Table 24.9 and 24.10) provided by [40]. The relationships can be expressed as follows:

$$
\begin{aligned}
\lambda & =3.63 \sigma+25, \\
c_{t} & =0.0347 \sigma+0.3,
\end{aligned}
$$

where the unit of $c_{t}$ is $10^{-3} \mathrm{~K}^{-1}$ and that of $\lambda$ is $\mathrm{W} \bullet \mathrm{m}^{-1} \mathrm{~K}^{-1}$. The fitted curve of $\lambda$ vs. $\sigma$ and that of $c_{t}$ vs. $\sigma$ are shown in Figure 6 , which is enough for the rough estimation of $\lambda$ and $c_{t}$. 


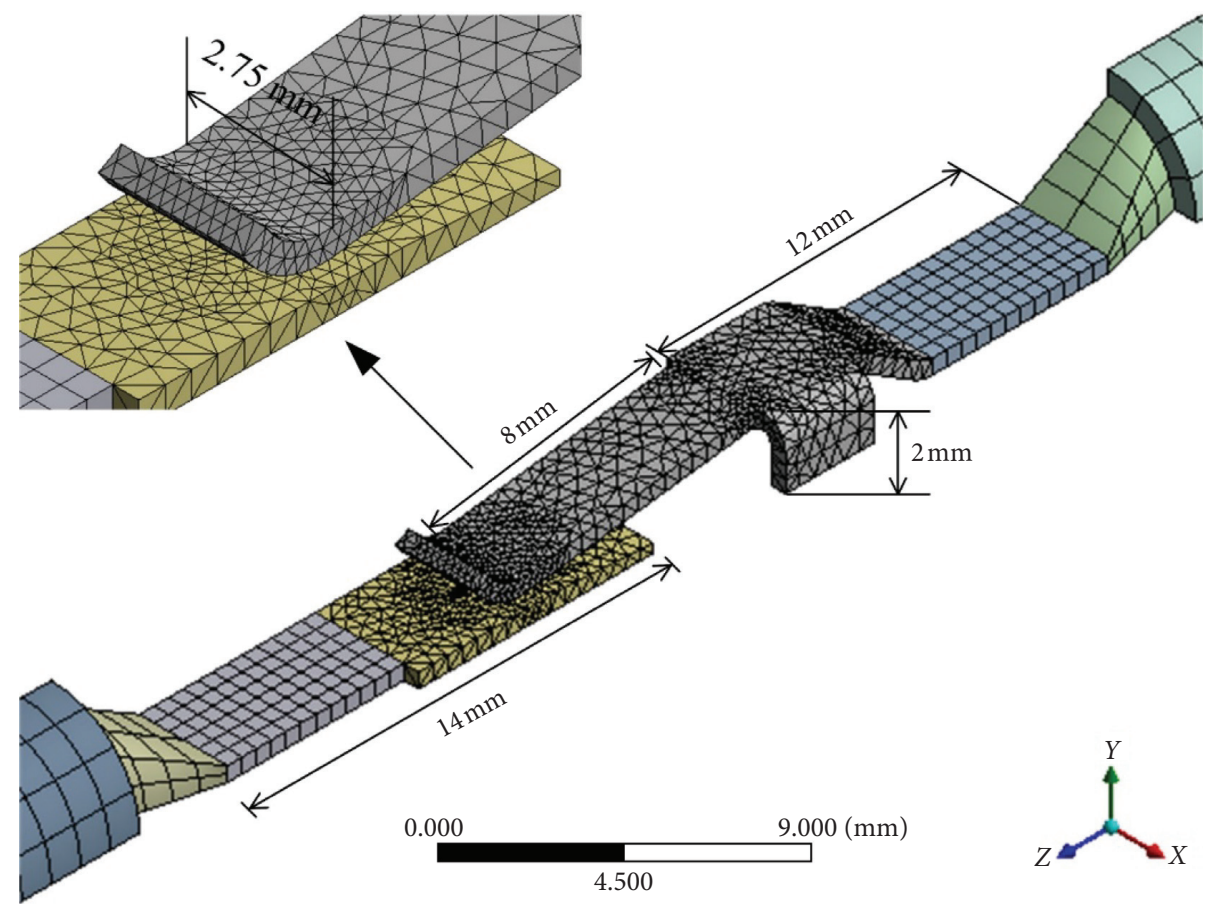

FIgURE 5: The $1 / 4$ geometrical FE model of the connector.

TABle 1: The material parameters of the cable [40-42].

\begin{tabular}{|c|c|c|c|c|c|c|}
\hline Part & Material & $\begin{array}{c}\text { Resistivity at } \\
20^{\circ} \mathrm{C}(\Omega \mathrm{m})\end{array}$ & $\begin{array}{c}\text { Temperature coefficient } \\
\text { of resistance }\left(\mathrm{K}^{-1}\right)\end{array}$ & $\begin{array}{c}\text { Thermal conductivity } \\
{\left[\mathrm{W} \cdot \mathrm{m}^{-1} \mathrm{~K}^{-1}\right]}\end{array}$ & Specific heat $\left[\mathrm{J} \bullet \mathrm{kg}^{-1} \mathrm{~K}^{-1}\right]$ & $\operatorname{Density}\left(\mathrm{g} / \mathrm{cm}^{3}\right)$ \\
\hline Copper wire & OHFC & $1.65 \mathrm{E}-8$ & $4.3 \mathrm{E}-3$ & 394 & 385 & 8.96 \\
\hline $\begin{array}{l}\text { Insulating } \\
\text { layer }\end{array}$ & XLPE & & & 0.4 & $\begin{array}{c}2000 \text { at } 20^{\circ} \mathrm{C}, 2600 \text { at } 75^{\circ} \mathrm{C}, \\
3600 \text { at } 100^{\circ} \mathrm{C} \text { (linear) }\end{array}$ & 0.91 \\
\hline
\end{tabular}

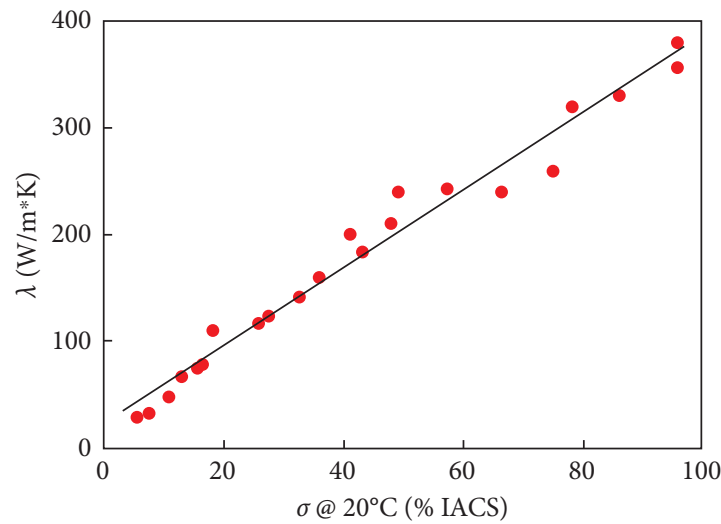

- Data points

- Fitted curve

(a)

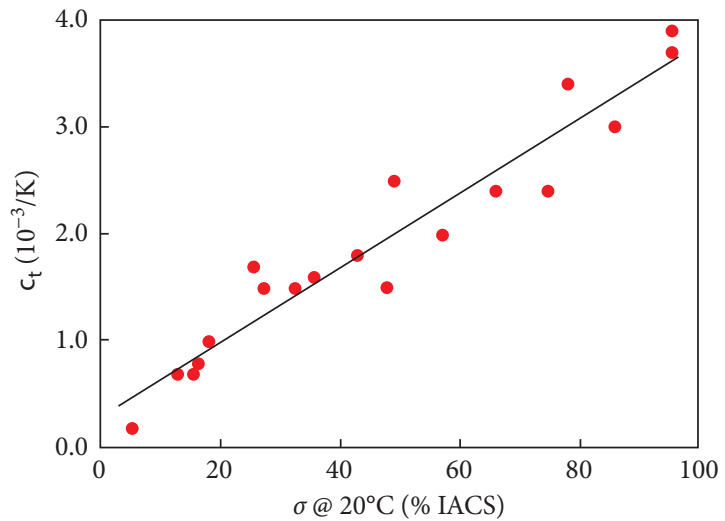

- Data points - Fitted curve

Figure 6: The relationship between $\lambda$ and $\sigma$ and that between $c_{t}$ and $\sigma$. (a) $\lambda$ vs. $\sigma$. (b) $c_{t}$ vs. $\sigma$.

Natural convection was considered. The coefficient of natural convective $h_{c}$ equals the following:

$$
h_{c}=\frac{\lambda_{a} N_{c}}{L_{c}},
$$

where $\lambda_{a}$ is the thermal conductivity of air, $N_{c}$ is the Nusselt number, and $L_{c}$ is characteristic length, respectively. The cable is a horizontal cylinder and its $N_{c}$ equals the following [43]: 


$$
N_{c}=\left(0.6+\frac{0.387 R_{a}^{1 / 6}}{\left(1+\left(0.559 / P_{r}\right)^{9 / 16}\right)^{8 / 27}}\right)^{2},
$$

where $R_{a}$ is the Rayleigh number and $P_{r}$ is the Prandtl number. During running, the connector is a vertical plane and its $N_{c}$ equals the following [44]:

$$
N_{c}=0.68+\frac{0.67 R_{a}^{1 / 4}}{\left(1+\left(0.492 / P_{r}\right)^{9 / 16}\right)^{4 / 9}} .
$$

Further, $R_{a}$ can be written as the product of $G_{r}$ (the Grashof number) and $P_{r}$ [45]. The value of $G_{r}$ equals the following [45]:

$$
G_{r}=g \beta_{a} \rho_{a}^{2}\left(T_{s}-T_{\infty}\right) \frac{L_{c}^{3}}{\mu_{a}^{2}}
$$

where $g$ is the gravity acceleration, $\beta_{a}$ is the thermal expansion coefficient of air, $\rho_{a}$ is the density of air, $T_{s}$ is surface temperature, $T_{\infty}$ is environment temperature, and $\mu_{a}$ is the dynamic viscosity of air, respectively. The value of $P_{r}$ equals the following [45]:

$$
P_{r}=\frac{c_{a} \mu_{a}}{\lambda_{a}}
$$

where $c_{a}$ is the specific heat of air.

The convective coefficient of the cable and the springblade are noted as $h_{a}$ and $h_{b}$, respectively. The difference between $T_{s}$ and $T_{\infty}$ is noted as $\Delta T$. Based on Equation (20) to Equation (24), the relationships between $h_{a}$ and $\Delta T$ and that between $h_{b}$ and $\Delta T$ were calculated. Results are shown in Figure 7. The parameters of air are temperature-dependent. At every value of $\Delta T$, the temperature value of air is seen as the average of $T_{s}$ and $T_{\infty}$ [45], and then the parameters of air can be determined.

Based on the FE model established above, the equilibrium temperature of the connector without $R_{c}$ under every value of $\sigma$ was calculated. Under every condition, the maximum temperature is on the spring, and with the increase of the distance to the spring, the value of temperature decreases. The minimum temperature is at the cable end, which equals the self-heating temperature of the cable. The values of the maximum bulk temperature on the spring and the minimum temperature at the cable end are plotted in Figure 8, showing that the value of the maximum bulk temperature varies with the value of $\sigma$ in an inverse proportion form and that the value of the minimum temperature keeps constant.

Taking the condition where $\sigma$ is $15 \%$ IACS for example, to exhibit the results, its bulk temperature contour is shown in Figure 9. The value of the maximum bulk temperature is $124^{\circ} \mathrm{C}$, which is a little lower than the maximum permissible value, i.e., $125^{\circ} \mathrm{C}$. Because in this condition, the value of $\rho_{s}$ is the highest and the value of $\lambda$ is the lowest, there exists a margin of $R_{c}$ for every condition.

Then, the electrothermal FE analysis with $R_{c}$ was carried out for every condition. At this substep, thermal power was loaded on the contact surface between the spring and the blade to simulate the heat generation by the contact resistance. Based on that, a value of the contact resistance for every condition was found out manually, which makes the maximum bulk temperature reach $125^{\circ} \mathrm{C}$. The relationship between this resistance value and the value of $\sigma$ is plotted, together with a constant value of $1.142 \mathrm{~m} \Omega$ determined by the maximum allowable supertemperature of the contacts. The results are shown in Figure 10, where the black solid line represents the relationship between the maximum allowable contact resistance $R_{c m}$ and $\sigma$. The results indicate that before about $24 \%$ IACS, the value of $R_{c m}$ is determined by the maximum allowable bulk temperature, and when the value of $\sigma$ exceeds about 24\% IACS, the value of $R_{c m}$ is determined by the maximum allowable supertemperature of the contacts.

The further substep is to calculate the minimum allowable contact force $F_{m}$ through contact analysis by Equation (1) under every condition. The known constant parameters, including that $\xi=0.2$ [46], $H=450 \mathrm{~N} / \mathrm{mm}^{2}$ [40], and the corresponding values of $\rho_{s}$ and $R_{c m}$ under every $\sigma$ were taken into Equation (1). The discrete results of $F_{m}$ are listed in Table 2.

It can be seen from Table 2 that when the value of $\sigma$ increases from $15 \%$ to $20 \%$ IACS, the value of $F_{m}$ displays a dramatic decrease.

Equation (1) is transformed to the following form:

$$
F_{m}=\frac{\xi \pi H \rho_{s}^{2}}{4 R_{c m}^{2}}=\frac{K_{c s}}{R_{c m}^{2} \sigma^{2}},
$$

where $K_{c s}$ is the production of constants.

When the value of $\sigma$ is between $15 \%$ and 20\% IACS, $R_{c m}$ is determined by the maximum allowable bulk temperature. In this section, it can be seen from Figure 8 that the maximum bulk temperature decreases obviously with the increase of $\sigma$. Thus, the margin left for the contact resistance increases obviously with the increase of $\sigma$. As a result, the increase of $\sigma$ leads to a dramatic increase in the value of $F_{m}$ because of the two quadratic components in the denominator. After this section, the decrease rate of the maximum bulk temperature becomes obviously smaller. With respect to the margin of the contact resistance, it increases slower and then becomes constant. Thus, the increase of $F_{m}$ becomes obviously slower.

In order to obtain a more accurate relationship between $F_{m}$ and $\sigma$, more values of $\sigma$ between $15 \%$ and $25 \%$ IACS were supplemented, under which the corresponding values of $R_{c m}$ and $F_{m}$ were calculated. The results are plotted in Figure 11 in the form of a natural logarithm.

The final substep to establish the material selection criterion of the connector is to find out the values of the minimum allowable material strength under every condition by structure stress analysis to build up the conductivitystrength relationship. Because the spring cannot be simplified as an ideal beam, the static structure FE analysis was adopted to determine the relationship between the restoring force and the maximum von Mises stress of the spring.

With respect to the FE model, the geometrical model was the same as that shown in Figure 5, except that the cable was 


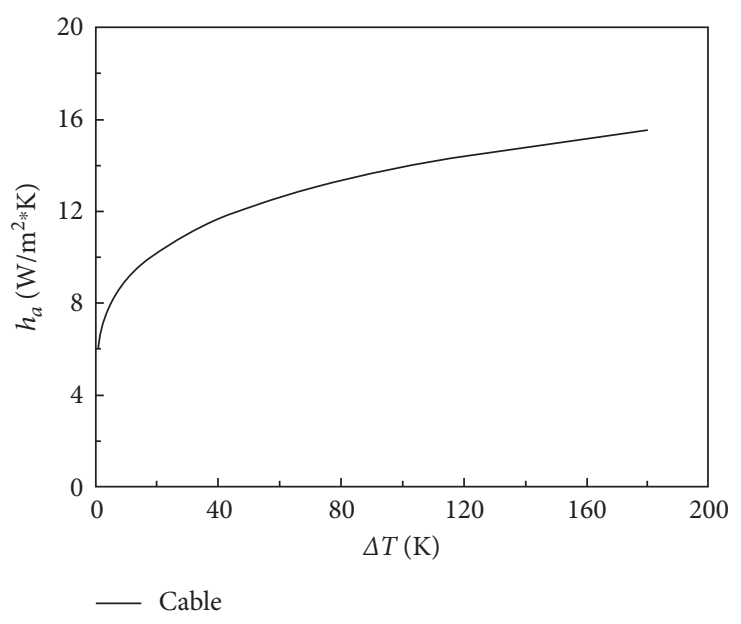

(a)

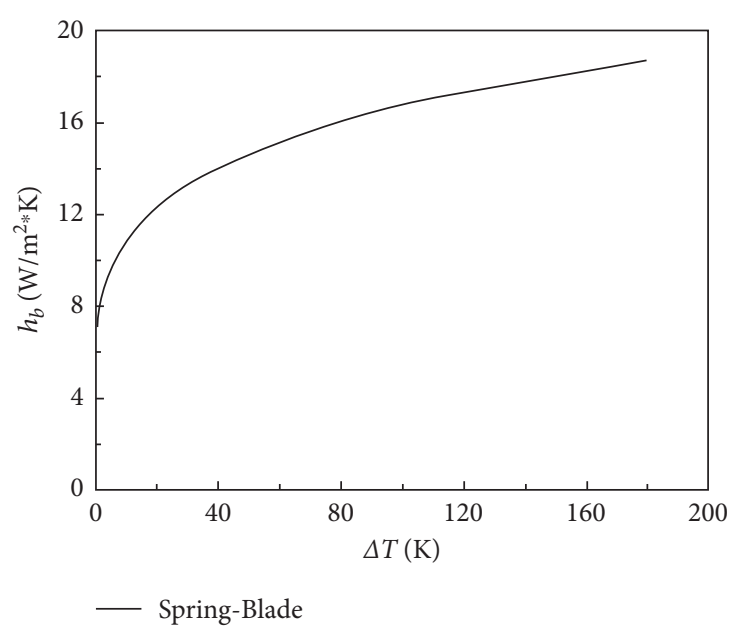

(b)

Figure 7: The relationships between $h$ and $\Delta T$. (a) $h_{a}$ vs. $\Delta T$. (b) $h_{b}$ vs. $\Delta T$.

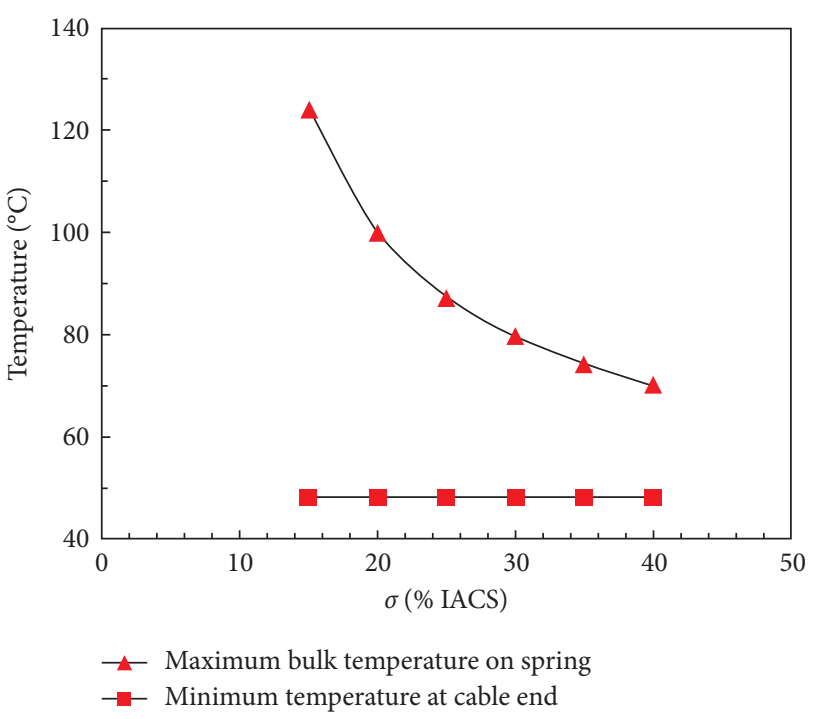

Figure 8: The values of maximum and minimum bulk temperature under every condition.

suppressed because it has no effect on the mechanical stress of the connector. The value of Young's modulus of the copper substrate is $120 \mathrm{GPa}$. The contact type between the spring and the blade was set as frictional. Frictionless support was set on all symmetry faces to prevent them from deforming on the normal direction. The end faces of the two terminations were fixed on the normal direction to avoid rigid movement. The interference between the blade and the spring was set as $0.1 \mathrm{~mm}$. The contact force $F$ and the maximum von Mises stress $\sigma_{m}$ of the spring were calculated by the FE model. The result of the stress distribution is shown in Figure 12. The maximum stress is at the root of the spring, which is consistent with an ideal cantilever beam.

The value of $\sigma_{m}$ is $196 \mathrm{MPa}$ and meanwhile, the value of $F$ is $1.24 \mathrm{~N}$. The value of this maximum stress should not be higher than the yield strength of the substrate material because this connector needs to be mated and unmated for a few cycles without causing the contact force loss. The spring structure is a linear system as long as the yield strength has not been exceeded. Thus, in elastic range, the relationship between $F$ and $\sigma_{m}$ was determined as follows:

$$
F=6.327 \times 10^{-3} \times \sigma_{m},
$$

where $F$ is in $\mathrm{N}$ and $\sigma_{m}$ is in $\mathrm{MPa}$.

Under every value of $\sigma$, the corresponding minimum allowable contact force $F_{m}$ was substituted into Equation (26) to determine the corresponding minimum allowable material strength $\sigma_{m y}$. The relationship between $\sigma_{m y}$ and $\sigma$ was obtained, which is shown in Figure 13, in the form of a natural logarithm.

For a certain material, if its $\left(\ln \sigma_{m y}, \sigma\right)$ locates in the shadow region shown in Figure 13, this material is feasible for the connector. The material parameters of $\mathrm{Cu}-20 \mathrm{Zn}-1.5 \mathrm{Ni}$ 0.34Si (CZNS) are listed in Table 3, where the temperature coefficient of resistance, thermal conductivity, Young's modulus, and density are referenced to $\mathrm{Cu}-20 \mathrm{Zn}$ [40]. Because $\left(\ln \sigma_{m y}, \sigma\right)$ of CZNS locates in the shadow region, CZNS can be adopted by this connector for function realization.

Secondly, the potential of CZNS for its use on this connector was evaluated. From Figure 13, it can be seen that the location of $\left(\ln \sigma_{m y}, \sigma\right)$ of CZNS is still away from the relationship line between $\sigma_{m y}$ and $\sigma$. It means that CZNS can make the maximum bulk temperature of the connector lower than $125^{\circ} \mathrm{C}$. The strength of CZNS can be fully reached for improving the contact force to reduce the temperature, which is realized by increasing the interference between the blade and the spring.

The safety coefficient is set as 1.2 , and thus, the maximum permissible stress of CZNS is $718 / 1.2=598 \mathrm{MPa}$. Based on Equation (26), the maximum contact force CZNS can provide was determined as $3.72 \mathrm{~N}$. Based on Equation (1), the corresponding value of $R_{c}$ was determined as $0.354 \mathrm{~m} \Omega$. By electrothermal FE analysis, the maximum bulk temperature of this connector under $0.354 \mathrm{~m} \Omega$ was determined as $98.8^{\circ} \mathrm{C}$, which is the initial temperature $T_{i}$. 


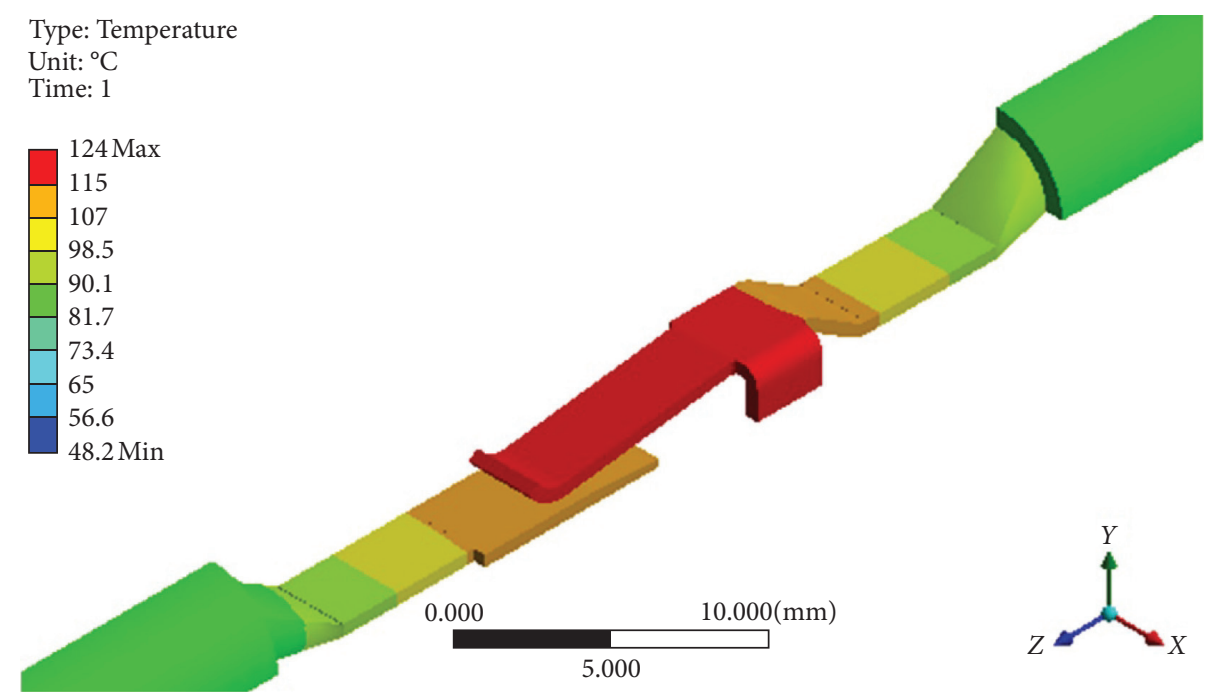

FIgURE 9: Temperature contour without $R_{c}$ when the value of $\sigma$ is $15 \%$ IACS.

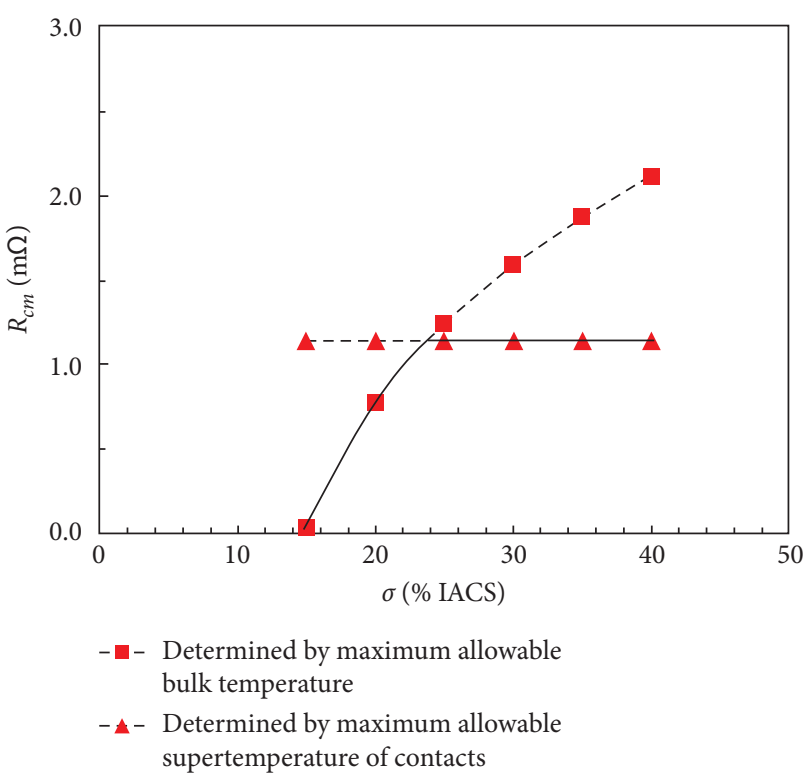

Figure 10: The relationship between $R_{c m}$ and $\sigma$.

TABLE 2: Discrete results of $F_{m}$ under different values of $\sigma$.

\begin{tabular}{lcc}
\hline$\sigma(\%$ IACS $)$ & $R_{c m}(\mathrm{~m} \Omega)$ & $F_{m}(\mathrm{~N})$ \\
\hline 15 & 0.036 & 852 \\
20 & 0.773 & 1.08 \\
25 & 1.142 & 0.33 \\
30 & 1.142 & 0.23 \\
35 & 1.142 & 0.17 \\
40 & 1.142 & 0.13 \\
\hline
\end{tabular}

4.2. Evaluation of Degradation Behavior. Firstly, the degradation of the connector under the mechanism of stress relaxation was evaluated. Based on electrothermal FE analysis, it was determined that the maximum bulk temperature reaches $125^{\circ} \mathrm{C}$ when $R_{c}=1.284 \mathrm{~m} \Omega$. Because $1.284 \mathrm{~m} \Omega>1.142 \mathrm{~m} \Omega, R_{c m}$ was determined as $1.142 \mathrm{~m} \Omega$. At

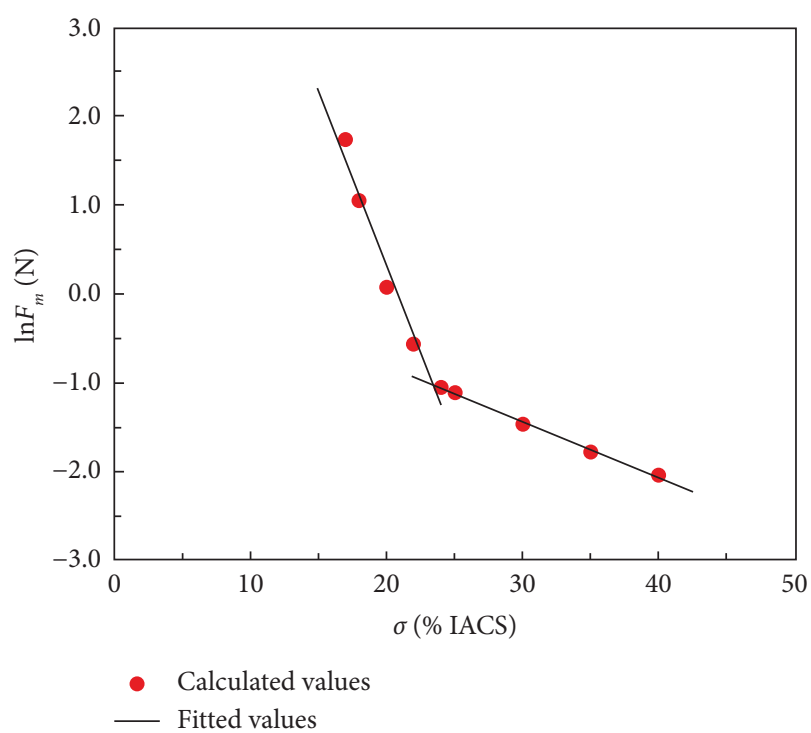

Figure 11: The relationship between $\ln F_{m}$ and $\sigma$.

this value, the maximum bulk temperature is $121^{\circ} \mathrm{C}$ at which the resistivity of CZNS is about $8.49 \mathrm{E}-8 \Omega \mathrm{m}$. Based on Equation (1), $F_{m}$ was determined as $0.39 \mathrm{~N}$. Thus, the value of $D_{u p}$ is 89.5. Then, the values of $k=0.146, A=6.1$, and $B=1238$ of brass [31] and the values of $t_{d}=43800 \mathrm{~h}$ and $T=383 \mathrm{~K}$ (the mean value of $371.95 \mathrm{~K}$ and $394.15 \mathrm{~K}$ ) were taken into Equation (2) to get that $D=83.8$. Because $83.8<89.5$, the reliability of the connector under stress relaxation meets the requirement.

Secondly, the behavior under the mechanism of thermal diffusion was evaluated. When the resistivity of CZNS is $8.49 \mathrm{E}-8 \Omega \mathrm{m}, R_{c}$ equals $0.370 \mathrm{~m} \Omega$. The allowable increment of $R_{c}$ equals the difference between $1.142 \mathrm{~m} \Omega$ and $0.370 \mathrm{~m} \Omega$, i.e., $0.772 \mathrm{~m} \Omega$. The values of $\Phi$ and $\varepsilon_{r}$ in Equation (12) are $5 \mathrm{eV}$ and 3 [37], respectively. The above parameters were taken into Equation (11) to Equation (13) to determine that the maximum allowable $d$ is about $5.8 \AA$. 


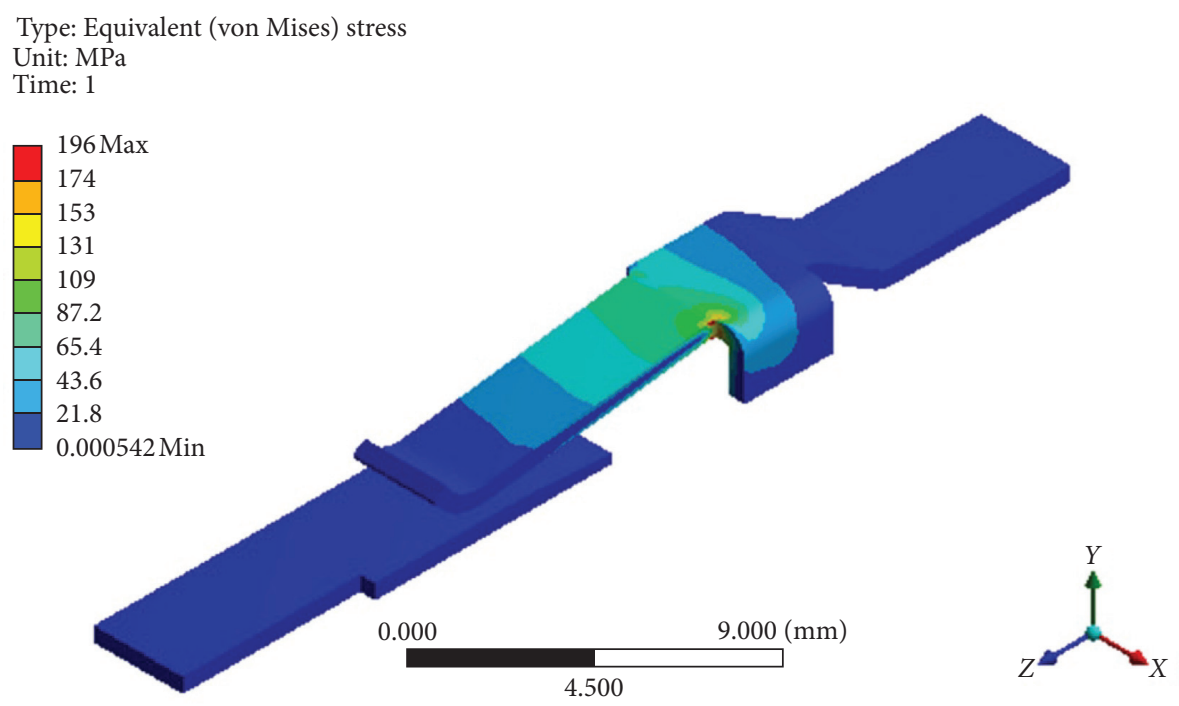

FIgURe 12: Von Mises stress contour when the interference is $0.1 \mathrm{~mm}$.

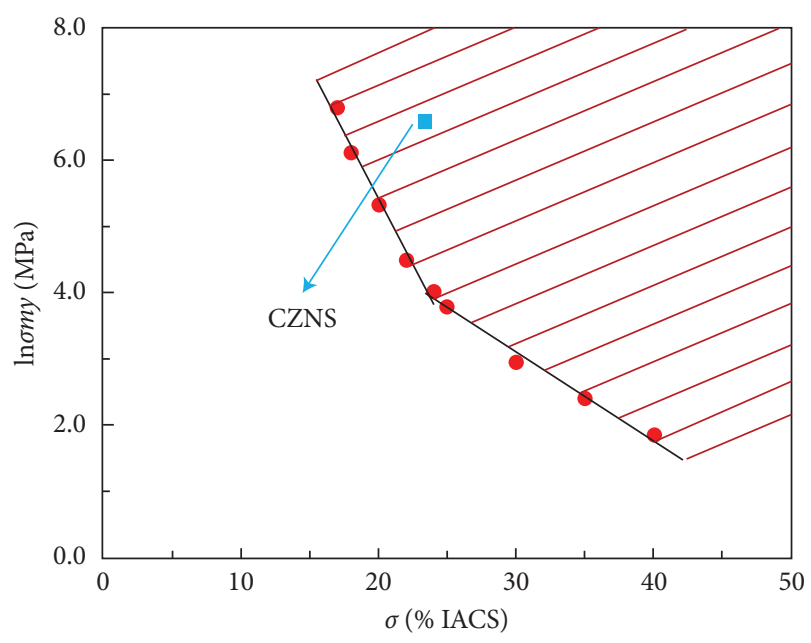

FIgURE 13: The relationship between $\ln \sigma_{m y}$ and $\sigma$.

TABLE 3: The material parameters of CZNS $[26,40]$.

\begin{tabular}{lc}
\hline Parameter & Value \\
\hline Electric conductivity at $20^{\circ} \mathrm{C}[\% \mathrm{IACS}]$ & 23.4 \\
Temperature coefficient of resistance $\left(\mathrm{K}^{-1}\right)$ & $1.5 \mathrm{E}-3$ \\
Thermal conductivity $\left[\mathrm{W} \bullet \mathrm{m}^{-1} \mathrm{~K}^{-1}\right]$ & 142 \\
Yield strength $(\mathrm{MPa})$ & 718 \\
Young's modulus $(\mathrm{GPa})$ & 120 \\
Specific heat $\left[\mathrm{J}^{-1} \mathrm{~kg}^{-1} \mathrm{~K}^{-1}\right]$ & 385 \\
Density $\left(\mathrm{g} / \mathrm{cm}^{3}\right)$ & 8.67 \\
\hline
\end{tabular}

Based on Equation (7) to Equation (9), the relationship between $C_{a}(t)$ and $t$ was calculated. The needed parameters are listed in Table 4. Based on Equation (10) $(n=2)$, the values of $V$ under a series values of $t_{s}$ were calculated, and the relationship between $V$ and $t_{s}$ was fitted as shown in Figure 14. This relationship can be expressed by the following:
TABLE 4: The parameters for calculating the relationship between $C_{a}(t)$ and $t[36]$.

\begin{tabular}{lc}
\hline Parameter & Value \\
\hline$h(\mu \mathrm{m})$ & 1 \\
$D_{0}\left(\mathrm{~cm}^{2} / \mathrm{s}\right)$ & $2.9 \mathrm{E}-3$ \\
$Q_{D}(\mathrm{eV})$ & 1.21 \\
$R\left[\mathrm{~J} \cdot \mathrm{mol}^{-1} \mathrm{~K}^{-1}\right]$ & 8.314 \\
$T(\mathrm{~K})$ & 383 \\
$t(\mathrm{~h})$ & $0-200000$ \\
\hline & \\
& \\
& $V=8 \times 10^{-5} \times t_{s}^{0.554}$.
\end{tabular}

Equation (27) was taken into the following formula:

$$
S=\int_{0}^{t_{d}} V d t_{s},
$$

to determine that $S=840 \mathrm{~h}$. According to Equation (10), it was determined that $d=3.5 \AA$, which is lower than $5.8 \AA$. Thus, the reliability of the connector under thermal diffusion meets the requirement.

Thirdly, with respect to sliding wear, the known parameter values that $k_{s}=17000 \mathrm{~g} / \mathrm{cm}$ [39], $F=372 \mathrm{~g}$, and $L=0.4 \mathrm{~cm}$ were taken into Equation (14) to determine that $N_{s}$ is 18 , which is far lower than 40 . Design improvement has to be carried out. Detail design methods are not in the scope of this article but will be briefly discussed later. Suppose that this design improvement has been finished to make $N_{s}$ higher than the specified value. Then, the known values of $k_{w}=2.43 \mathrm{E}-4$ [47], $\xi=0.2, F=3.72 \mathrm{~N}$, and $H=450 \mathrm{~N} / \mathrm{mm}^{2}$ were taken into Equation (17) to get that $h_{w}=0.0175 \mu \mathrm{m}$. Because $h(1 \mu \mathrm{m})$ is higher than $20 h_{w}(0.35 \mu \mathrm{m})$, the thickness of gold is enough.

4.3. Evaluation of Anti-Overcurrent Ability. Firstly, a steadystate electrothermal FE model was built, based on which the values of voltage drop, noted as $V_{d 1}-V_{d 5}$, across the five 


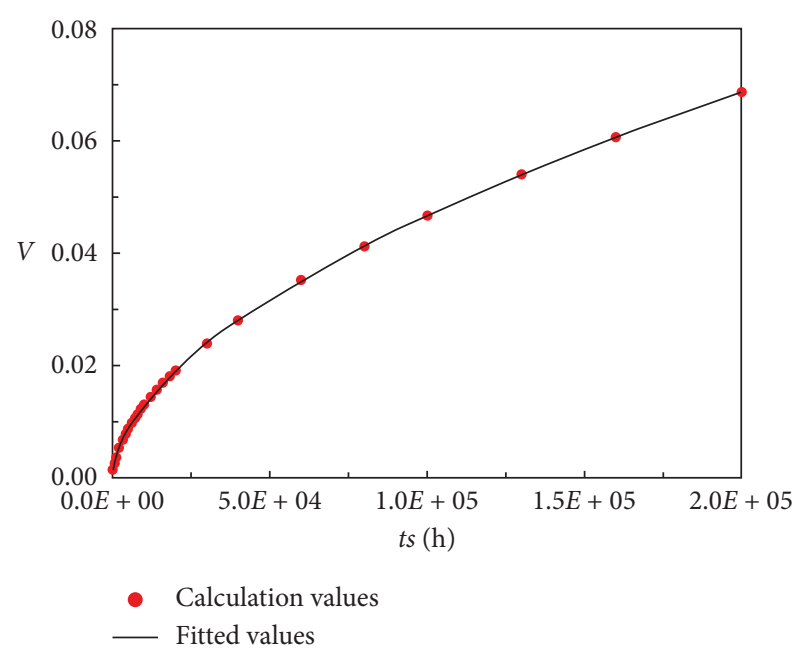

Figure 14: The calculation values of $V$ and fitted curve of $V$ vs. $t_{s}$.

parts of the connector were calculated. These five parts are shown in Figure 15.

The rated current is known constant, and thus, the heat generation power, noted as $P_{1}-P_{5}$, of these five parts can be calculated. A steady-state thermal FE model was built, and $P_{1}$ - $P_{5}$ were loaded at these five parts, respectively. The steadystate distribution of the connector bulk temperature was obtained. Next, a transient thermal FE model was built, whose initial state is the bulk temperature distribution of the steady-state thermal FE model. In the transient thermal FE model, the values of $P_{1}-P_{5}$ at different levels of overcurrent were loaded to calculate the transient responses of the bulk temperature, respectively.

Three groups of work conditions were analyzed. Under every condition, the time for the maximum bulk temperature to reach the specified upper limit, i.e., $140^{\circ} \mathrm{C}$, was read and noted as $t_{v}$. In these three groups, $R_{c}$ is one, two, and three times the initial value of $0.354 \mathrm{~m} \Omega$, representing the different degradation levels of the connector. In each work condition, four values of current $I$, which are 1.4, 1.6, 1.8, and 2.0 times of the rated current, were considered. They represent the different levels of the overcurrent.

The results of $t_{v}$ under all work conditions are listed in Table 5, showing that the higher $I$ or $R_{c}$, the shorter $t_{v}$, and that $R_{c}$ has a significantly effect on the anti-overcurrent ability of the connector.

The relationships between $\ln t_{v}$ and $\ln \left(I_{v}-I_{L}\right)$ under the three work conditions were fitted and plotted in Figure 16 where $I_{v}$ is the overcurrent, and $I_{L}$ is the current at which the maximum steady-state bulk temperature of the connector reaches $140^{\circ} \mathrm{C}$. No matter how much the value of $R_{c}$ is, the relationship between $t_{v}$ and $I_{v}$ can be expressed by the following:

$$
t_{v}=\frac{e^{q}}{\left(I_{v}-I_{L}\right)^{p}}
$$

where $p$ and $q$ are constants related to material and $R_{c}$. The values of $p, q$, and $I_{L}$ under the three work conditions are listed in Table 6.

\section{Discussion}

The reliability evaluation of the connector, that is, to adopt CZNS as substrate material, has been completed, based on the framework shown in Figure 1. The evaluation results are useful for the design improvement of the connector. Although a detailed design is beyond the scope of this article, some meaningful discussion is presented as follows.

It has been pointed out that for this connector, design improvement on the reliability under the mechanism of sliding wear should be carried out because $N_{s}$ is not high enough. For increasing $N_{s}$, possible choices are increasing $L$, increasing $k_{s}$ by lubrication, and decreasing $F$. Whether these methods can be adopted depends not only on their effectiveness but also on the effects which they have on the other aspects of reliability. Increasing $L$ decreases the bulk resistance of the connector and thus decreases temperature. By this method, stress relaxation and thermal diffusion can also be alleviated. Increasing $k_{s}$ just changes the surface state of the contacts and has no negative effect on the reliability under stress relaxation and thermal diffusion. Decreasing $F$ increases $N_{s}$, but it is bad for the reliability under stress relaxation and thermal diffusion. One has to be careful when this method is to be considered to be adopted. What has to be ensured is that if $F$ is reduced, the validity of the reliability under stress relaxation and thermal diffusion should be retained. Nevertheless, these methods will not negatively affect existing design choices, which means that the evaluation framework proposed in this article helps the design process be smooth.

The assessment on $h_{w}$ has been done based on the supposition that the needed design improvement has been finished. The design improvement will change the values of the parameters in Equation (17). However, the values used in this article were not updated. One might doubt that whether the result of the evaluation is valid. Actually, all these methods can make $h_{w}$ lower, which means that the evaluation result will be better if the updated values have been adopted. Thus, the evaluation results given by this article can always keep validity because the worst work condition has been considered.

Based on the above analysis, it can be concluded that the framework is very friendly to the design of connector. This is because the steps of this framework have been elaborately devised according to two important factors. One is the interplay between the degradation mechanisms of connector, and the other is the possible palliative measures aiming at every mechanism. At a certain design step, even if the reliability under a certain mechanism does not meet the requirement, the design improvement methods aiming at this mechanism will have negative effects neither on the other aspects of reliability that have been proven satisfactory nor on the aspects of reliability which is to be assessed subsequently. 


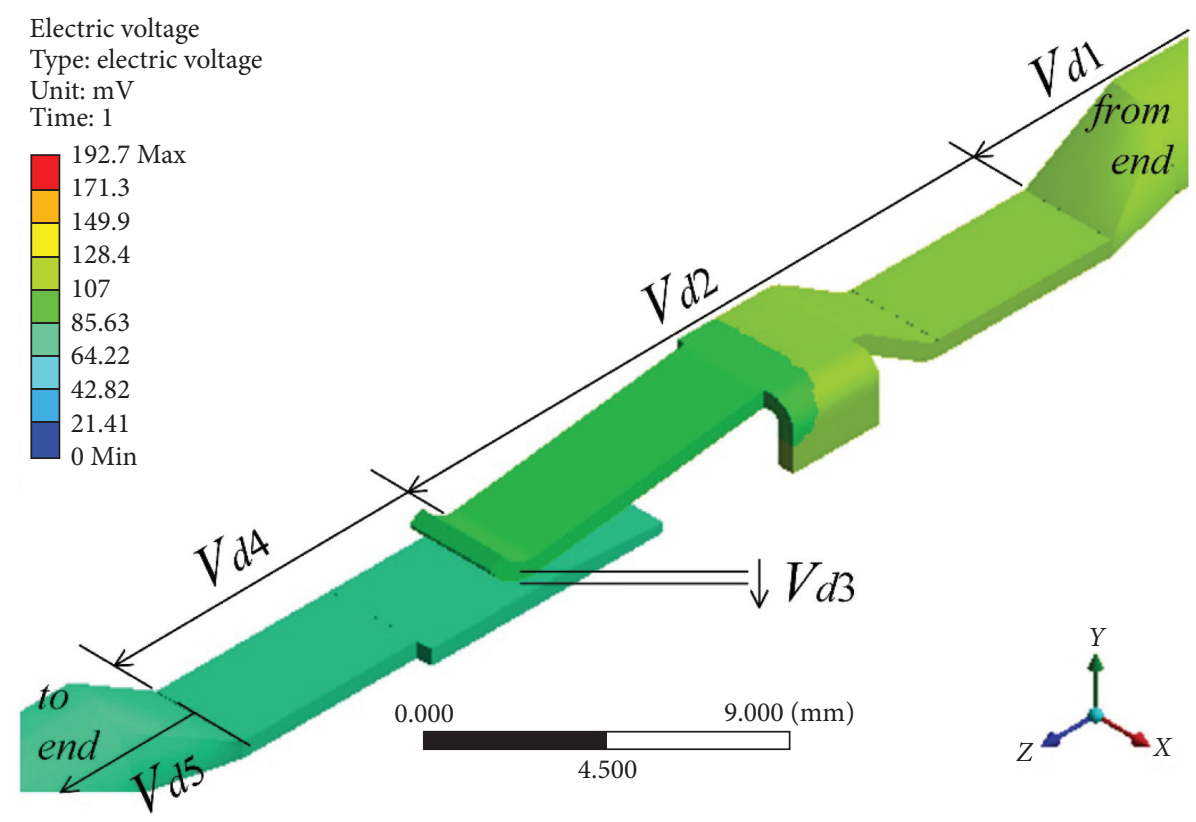

FIgURE 15: The five parts of the connector.

TABLE 5: The results of $t_{v}$ under all the work conditions.

\begin{tabular}{lccc}
\hline Work condition & $R_{c}(\mathrm{~m} \Omega)$ & $I(\mathrm{~A})$ & $t_{v}(\mathrm{~s})$ \\
\hline 1 & 0.354 & 98 & 154.8 \\
2 & 0.354 & 112 & 29.4 \\
3 & 0.354 & 126 & 9.0 \\
4 & 0.354 & 140 & 4.8 \\
5 & 0.708 & 98 & 35.0 \\
6 & 0.708 & 112 & 6.5 \\
7 & 0.708 & 126 & 3.0 \\
8 & 0.708 & 140 & 1.7 \\
9 & 1.062 & 98 & 5.4 \\
10 & 1.062 & 112 & 1.9 \\
11 & 1.062 & 126 & 0.9 \\
12 & 1.062 & 140 & 0.5 \\
\hline
\end{tabular}

For instance, suppose that there is another material to be evaluated and only the reliability under the mechanism of thermal diffusion is not satisfactory. Two palliative measures are increasing the thickness of gold and adopting nickel as an underplate [28]. These two methods do not influence the reliability under the mechanism of stress relaxation because they do not change temperature. Adopting nickel does not affect $N_{s}$, and meanwhile, it can decrease $h_{w}$ through reducing $k_{w}$. Increasing the gold thickness does not affect $N_{s}$ and it can strengthen the endurance of the contact surface. One can conclude that either adopting nickel or increasing the thickness of gold do not have negative effects on the reliability under the mechanism of sliding wear. Further, no matter what method to be adopted, the anti-overcurrent ability of the connector will not be changed because the connector behaviors of heat generation and transfer are not changed.

It has to be pointed out that although only CZNS has been evaluated for its feasibility on the connector, this does

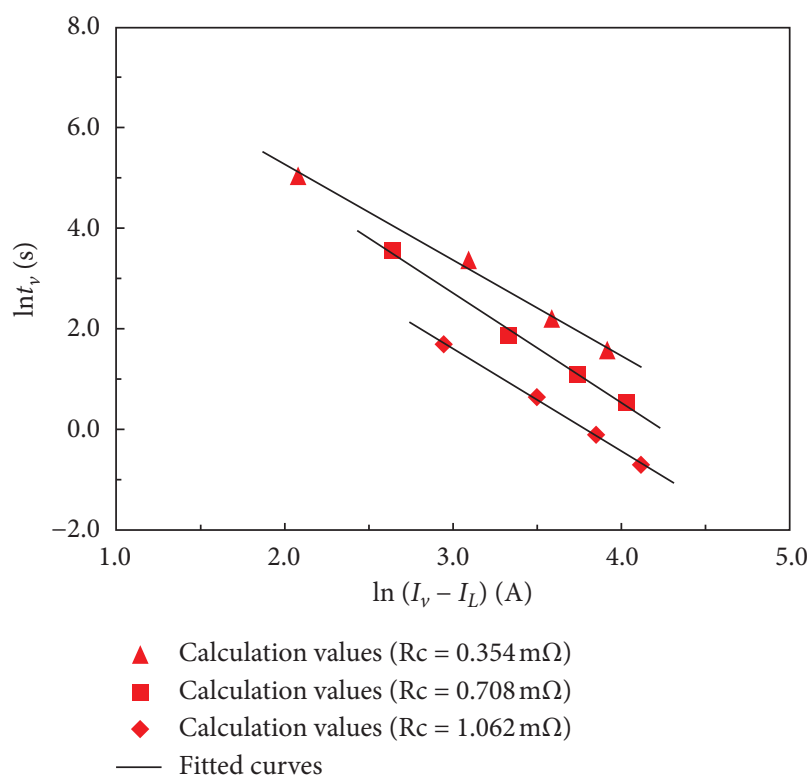

FIgURE 16: The relationships between $\ln t_{v}$ and $\ln \left(I_{v}-I_{L}\right)$ under the three work conditions.

TABLE 6: The values of $p, q$, and $I_{L}$ under the three work conditions.

\begin{tabular}{lccc}
\hline$R_{c}(\mathrm{~m} \Omega)$ & $q$ & $p$ & $I_{L}(\mathrm{~A})$ \\
\hline 0.354 & 9.07 & 1.91 & 90 \\
0.708 & 9.26 & 2.18 & 84 \\
1.062 & 7.70 & 2.03 & 79 \\
\hline
\end{tabular}

not mean that the material selection criterion built in this article only applies to this material. Any material can be evaluated by plotting the coordinate of $\left(\ln \sigma_{m y}, \sigma\right)$ on the graph shown in Figure 13 for its feasibility on the connector. 
In some situations, there might be a few materials to be evaluated. They can be simultaneously plotted on that graph. Thus, the material selection criterion provides a convenient and fast way to screen out infeasible materials.

Besides the advantages of integration, well-organized order, and quantification, the proposed approach has good scalability. Although not provided in this article, many new methods and models can be added to the framework of this approach to enhance its availability. This approach is modularized and every module is made up of a series of steps. The output of one module can be used as the input of the next module, or the output of one step can be adopted by the next step as input, no matter how the output is obtained. Any single module, or step in a module, can be able to be solely used. For example, just the first module of this approach is needed to be adopted if only the function realization of the connector is to be evaluated. Any method or model can be inserted into this module, so long as this variation will not change the corresponding output, i.e., an initial design of the structure and material of connector to be evaluated, of this module.

\section{Conclusions}

A systematic approach for the reliability evaluation of electric connector was proposed, the framework of which consists of three modules. Each module evaluates one aspect of the reliability of connector, including the initial state after function realization, the degradation behavior, and the antioverload performance. After the methods and models needed by the evaluation had been built, the proposed approach was successfully applied to an existing bladespring connector, the substrate material of which was required to be replaced with a newly developed copper alloy called $\mathrm{Cu}-20 \mathrm{Zn}-1.5 \mathrm{Ni}-0.34 \mathrm{Si}$.

The results show that the $\mathrm{Cu}-20 \mathrm{Zn}-1.5 \mathrm{Ni}-0.34 \mathrm{Si}$ applies to the connector for realizing the specified function. However, the reliability under the mechanism of sliding wear should be improved by increasing the insertion depth of the blade and lubrication or properly decreasing contact force.

The material selection criterion proposed can judge rapidly whether a certain material is applied to the substrate of the connector. This criterion correlates the electric conductivity performance with the mechanical strength performance of the material, which are the two most important parameters that the function realization of the connector requires. This novel method for establishing the criterion can be adopted not only by the connector studied here but also by other congener connectors. No matter in a new design case or a design improvement case, this method can help reduce the consuming time of material selection from big databases.

On the part of degradation behavior evaluation, a novel model for assessing reliability under the mechanism of thermal diffusion was built and verified by existing experimental data. This model can quantitatively calculate the thickness of oxidation film upon the surface of contacts in a gold-copper system. Based on that, the contact resistance of the contacts can be determined, which can be further used to evaluate the validity of surface prevention. Then, whether the current design choice is overdesigned or insufficient can be judged to guide the design improvement, which might be needed.

Based on FE analysis, the anti-overcurrent ability of the connector was assessed. Results show that overcurrent level and contact resistance are the two main factors of this ability. The duration of the overcurrent that the connector can endure can always be expressed by a power function of current, which can be used to analyze the extreme degradation level and the overcurrent level that the connector can accept.

Some limitations of this work have to be presented to avoid confusion that the users of this approach might meet. Overall, the electric connector can be classified into two categories, i.e., signal and power connectors. The former can be further classified into low- and high-frequency connectors. This proposed approach does not apply to the highfrequency connectors. After the current frequency has reached the level where the difference between the size of the connector and the wavelength of the signal cannot be ignored, the connector should be regarded as part of an electromagnetic transmission line [48], but not a lumped parameter component anymore. Under this situation, the concerns are the issues of signal reflection, insertion loss, and crosstalk [48], but not the temperature rise, contact resistance, and contact force, which are the main indicators of connector performance in this approach.

Temperature is the most important indicator of whether the connector is at a reliable state, especially for power connectors. Thus, in this approach, the temperature is used as the main parameter for evaluating the function and reliability of the connector. In practice, designers might meet some cases where the connector contains insulation housing. In these cases, the effect of not only the metal terminations, which have been considered in our work but also the housing on the temperature of the connector should be taken into consideration. If the approach proposed here is adopted on the connector with housing, the accuracy of results will decrease unless the framework has been modified, e.g., adding the influence of the existence of the housing on the maximum allowable temperature or the structure restriction on the springs and blade by the housing.

In this work, the methods and models provided for evaluating the degradation behavior of the connector make the degradation evaluation module of the framework directly apply to the connector whose contact surface finish is gold. In practice, the surface material of contacts might be different. For instance, tin and its alloys are also often used as the finish of contacts. Under this situation, the typical degradation mechanisms of contact surface are intermetallics [49] and fretting wear [50], but not thermal diffusion and sliding wear anymore. Thus, more methods and models for the analysis of degradation mechanisms should be supplemented into the framework to make this approach apply to more types of connectors. In this work, a specific analysis was done to determine the degradation mechanisms which will happen on the studied connector, according to 
the material, structure, and environment. In practice, the extensive application makes the work conditions of the connector very various. If a general method, as a module before the degradation behavior evaluation module, can be added to the proposed framework to make the analysis process easier and faster, this approach will be more systematic and can more widely be used in practical applications.

\section{Data Availability}

The data used to support the findings of this study are available from the corresponding author upon request.

\section{Conflicts of Interest}

The authors declare that there are no conflicts of interest regarding the publication of this paper.

\section{Acknowledgments}

The study was financially supported by the National Key Research and Development Project of Ministry of Science and Technology (No. 2018YFF01011604) and National Natural Science Foundation of China (No. 61674017).

\section{References}

[1] Y. W. Park, H. G. Joo, and K. Y. Lee, "Effect of intermittent fretting on corrosion behavior in electrical contact," Wear, vol. 268, no. 3-4, pp. 353-360, 2010.

[2] S. M. Glista, W. F. Burns, and B. Lessard, "F-22 lessons learned: line replaceable module (LRM) electrical connector an investigation of vibration-induced contact wear and electro static discharge hardening," ASME International Mechanical Engineering Congress and Exposition, vol. 5, pp. 327-340, 2009.

[3] D. Hughes, "Catastrophic uncommanded closures of engine feedline fuel valve from corroded electrical connectors," in Proceedings of the International Corrosion Conference Series, Orlando, FL, USA, 2000.

[4] M. Braunovic, "Overheating of flexible tinned copper connectors," IEEE Transactions on Components and Packaging Technologies, vol. 24, no. 3, pp. 384-388, 2001.

[5] G. P. Luo, J. G. Lu, and J. G. Zhang, "Failure analysis on bolttype power connector's application," in Proceedings of the 45th IEEE Holm Conference on Electrical Contacts, pp. 77-86, Pittsburgh, PA, USA, October 1999.

[6] S. C. Fok and W. P. Yap, "A case-based design system for the conceptual design of electrical connectors," International Journal of Advanced Manufacturing Technology, vol. 20, no. 11, pp. 787-798, 2002.

[7] M. Buggy and C. Conlon, "Material selection in the design of electrical connectors," Journal of Materials Processing Technology, vol. 154, pp. 213-218, 2004.

[8] M. Blauth, F. Berger, and J. Song, "Optimization of the number of contact springs in a connector by means of analytical and numerical analysis," in Proceedings of the 27th International Conference On Electrical Contacts, pp. 496-501, Dresden, Germany, June 2014.

[9] R. S. Mroczkowski, "Concerning reliability modeling of connectors," in Proceedings of the 44th IEEE Holm Conference on Electrical Contacts, pp. 57-68, Arlington, VA, USA, September 1998.

[10] S. Jörgens and H. Taschke, "Accelerated design processes for insulation displacement connectors using the finite-elementmethod," in Proceedings Of the 23rd International Conference On Electrical Contact Together with the 6th International Session On Electromechanical Devices, pp. 197-202, Sendai, Japan, June 2006.

[11] D. McGowan, "Power connector evaluation for thermal performance," in Proceedings Of the 2008 23rd Annual IEEE Applied Power Electronics Conference And Exposition, APEC, pp. 1597-1601, Austin, TX, USA, February 2008.

[12] K.-C. Liao and C.-C. Chang, "Applications of damage models to durability investigations for electronic connectors," $M a$ terials \& Design, vol. 30, no. 1, pp. 194-199, 2009.

[13] Q. Feng, K. P. Zhao, B. Sun et al., "Electrical connector ultimate vibration load quantization and application Technology," Chemical Engineering Transactions, vol. 33, pp. 565-570, 2013.

[14] N. Zhu, G. F. Zhai, and Z. Y. Guo, "Research on contact reliability design of electrical connector contact," in Proceedings of 2019 International Conference on Quality, Reliability, Risk, Maintenance, and Safety Engineering, Zhangjiajie, Hunan, China, August 2019.

[15] M. Braunovic, "Effect of connection design on the contact resistance of high power overlapping bolted joints," IEEE Transactions on Components and Packaging Technologies, vol. 25, no. 4, pp. 642-650, 2002.

[16] E. R. Crandall, F. Schabert, H. Schmidt et al., "New LITESURF plating for the mitigation of whisker risks in press-fit applications," in Proceedings Of the 63rd IEEE Holm Conference On Electrical Contacts, pp. 132-138, Denver, CO, USA, September 2017.

[17] H. H. Law, J. Sapjeta, and E. S. Sproles, "Protective treatments for gold-flashed contact finishes with a nickel substrate," IEEE Transactions on Components, Packaging, and Manufacturing Technology: Part A, vol. 18, no. 2, pp. 405-408, 1995.

[18] X. Wang and L.-j. Xu, "Finite element model analysis of thermal failure in connector," Journal of Zhejiang UniversitySCIENCE A, vol. 8, no. 3, pp. 397-402, 2007.

[19] M. Antler, M. Drozdowicz, and C. Haque, "Connector contact materials: effect of environment on clad palladium, palladium-silver alloys, and gold electrodeposits," IEEE Transactions on Components, Hybrids, and Manufacturing Technology, vol. 4, no. 4, pp. 482-492, 1981.

[20] M. Myers, "The performance implications of silver as a contact finish in traditionally gold finished contact applications," in Proceedings Of the 55th IEEE Holm Conference On Electrical Contacts, pp. 307-315, Vancouver, BC, Canada, September 2009.

[21] Y. Nomura, Y. Saitoh, K. Furukawa et al., "Press-Fit connector for automobile ECUs," in Proceedings of the 52nd IEEE Holm Conference on Electrical Contacts, pp. 211-216, Montreal, QC, Canada, September 2006.

[22] M. P. Larsson, "Improved contact resistance stability in a MEMS separable electrical connector," in Proceedings of SPIEThe International Society For Optical Engineering, Brisbane, Australia, January 2006.

[23] L. Revay, "Surface accumulation rate of diffusing species on thin gold electroplates," IEEE Transactions on Components, Hybrids, and Manufacturing Technology, vol. 15, no. 5, pp. 870-875, 1992.

[24] M. Oberst, S. Schlegel, S. Grossmann, H. Willing, and R. Freudenberger, "Impact of the formation of intermetallic 
compounds in current-carrying connections," IEEE Transactions on Device and Materials Reliability, vol. 20, no. 1, pp. 157-166, 2020.

[25] P. Reid, C. Mittelstadt, and T. Faber, "Electric vehicle conductive charge couplers," in Proceedings Of the 60th IEEE Holm Conference On Electrical Contacts, New Orleans, LA, USA, October 2014.

[26] W. Chen, Y. Jia, J. Yi, M. Wang, B. Derby, and Q. Lei, “Effect of addition of $\mathrm{Ni}$ and $\mathrm{Si}$ on the microstructure and mechanical properties of $\mathrm{Cu}-\mathrm{Zn}$ alloys," Journal of Materials Research, vol. 32, no. 16, pp. 3137-3145, 2017.

[27] N. Lucke, S. Grobmann, H. Lobl, T. Ledermann, and G. Freudiger, "Long-term behaviour of plug-in connectors with copper beryllium contact lamellas depending on stress relaxation," in Proceedings of the 56th IEEE Holm Conference on Electrical Contacts, pp. 537-542, Charleston, SC, USA, October 2010.

[28] M. Antler, "Gold plated contacts: effect of thermal aging on contact resistance," in Proceedings of the 43rd IEEE Holm Conference on Electrical Contacts, pp. 121-131, Philadelphia, PA, USA, September 1997.

[29] L. Y. Yao, "Research on the key influence factors of power connector design," Master Thesis, Beijing University of Posts and Telecommunications, Beijing, China, 2018.

[30] R. S. Timsit, "Electrical contact resistance: fundamental principles," in Electrical Contacts: Principles and Applications, P. G. Slade, Ed., CRC Press, Boca Raton, Florida, USA, 2014.

[31] R. D. Malucci, "Accelerated testing of tin-plated copper alloy contacts," IEEE Transactions on Components and Packaging Technologies, vol. 22, no. 1, pp. 53-60, 1999.

[32] ASTM International, Standard Test Methods for Stress Relaxation Tests for Materials and Structures, ASTM International, West Conshohocken, Pennsylvania, USA, 2013.

[33] M. R. Pinnel, H. G. Tompkins, and D. E. Heath, "Oxidation of copper in controlled clean air and standard laboratory air at $50^{\circ} \mathrm{C}$ to $150^{\circ} \mathrm{C}$," Applications of Surface Science, vol. 2, no. 4 , pp. $558-577,1979$.

[34] P. G. Slade, "Introduction to contact tarnishing and corrosion," in Electrical Contacts: Principles and Applications, P. G. Slade, Ed., CRC Press, Boca Raton, Florida, USA, 2nd edition, 2014.

[35] M. R. Pinnel, H. G. Tompkins, and D. E. Heath, "Oxidation kinetics of copper from gold alloy solution at $50^{\circ}-150^{\circ} \mathrm{C}$," Journal of the Electrochemical Society, vol. 126, no. 10, pp. 1798-1805, 1979.

[36] P. M. Hall, J. M. Morabito, and N. T. Panousis, "Interdiffusion in the $\mathrm{CuAu}$ thin film system at $25^{\circ} \mathrm{C}$ to $250^{\circ} \mathrm{C}$," Thin Solid Films, vol. 41, no. 3, pp. 341-361, 1977.

[37] R. Holm, "Tunnel effect," In Electric Contacts: Theory and Application, Springer-Verlag Berlin Heidelberg, New York, NY, USA, pp. 118-134, 1967.

[38] M. Antler, "Tribological properties of gold for electric contacts," IEEE Transactions on Parts, Hybrids, and Packaging, vol. 9, no. 1, pp. 4-14, 1973.

[39] M. Antler, "Sliding wear of metallic contacts," IEEE Transactions on Components, Hybrids, and Manufacturing Technology, vol. 4, no. 1, pp. 15-29, 1981.

[40] P. G. Slade, "Useful Electric Contact Information," in Electrical Contacts: Principles and Applications, P. G. Slade, Ed., CRC Press, Boca Raton, Florida, USA, 2nd edition, 2014.

[41] Y. F. Zhao, Z. Z. Han, Y. Xie et al., "Correlation between thermal parameters and morphology of cross-linked polyethylene," IEEE Access, vol. 8, pp. 19726-19736, 2020.
[42] H. K. Lv, T. H. Lu, L. Q. Xiong et al., “Assessment of thermally aged XLPE insulation material under extreme operating temperatures," Polymer Testing, vol. 88, Article ID 106569, 2020.

[43] S. W. Churchill and H. H. S. Chu, "Correlating equations for laminar and turbulent free convection from a horizontal cylinder," International Journal of Heat and Mass Transfer, vol. 18, no. 9, pp. 1049-1053, 1975.

[44] S. W. Churchill and H. H. S. Chu, "Correlating equations for laminar and turbulent free convection from a vertical plate," International Journal of Heat and Mass Transfer, vol. 18, no. 11, pp. 1323-1329, 1975.

[45] F. Capelli, J. R. Riba, and J. Sanllehí, "Finite element analysis to predict temperature rise tests in high-capacity substation connectors," IET Generation, Transmission \& Distribution, vol. 11, no. 9, pp. 2283-2291, 2017.

[46] R. Holm, The Load Bearing Contact Area As A Function Of Load and Elastic and Plastic Properties Of The Members, Springer-Verlag Berlin Heidelberg, New York, NY, USA, pp. 29-39, 1967.

[47] N. Ohmae and E. Rabinowicz, "The wear of the noble metals," A S L E Transactions, vol. 23, no. 1, pp. 86-92, 1980.

[48] R. S. Timsit, "High speed electronic connector design: a review of electrical and electromagnetic properties of passive contact elements -- Part 1," IEICE Transactions on Electronics, vol. E91-C, no. 8, pp. 1178-1191, 2008.

[49] M. Braunovic, "Effect of intermetallic phase on the performance of tin-plated copper connections and conductors," in Proceedings Of the 49th IEEE Holm Conference On Electrical Contacts, pp. 124-131, Washington, DC, USA, October 2003.

[50] Y. W. Park, T. S. N. Sankara Narayanan, and K. Y. Lee, "Fretting corrosion of tin-plated contacts," Tribology International, vol. 41, no. 7, pp. 616-628, 2008. 